\title{
The Role of Warm Conveyor Belts for the Intensification of Extratropical Cyclones in Northern Hemisphere Winter ${ }^{\mathscr{A}}$
}

\author{
Hanin Binder, MaXi BoetTcher, Hanna JoOs, AND Heini WeRnli \\ Institute for Atmospheric and Climate Science, ETH Zürich, Zurich, Switzerland
}

(Manuscript received 1 October 2015, in final form 8 July 2016)

\begin{abstract}
The role of warm conveyor belts (WCBs) and their associated positive low-level potential vorticity (PV) anomalies are investigated for extratropical cyclones in Northern Hemisphere winter, using ERA-Interim and composite techniques. The Spearman correlation coefficient of 0.68 implies a moderate to strong correlation between cyclone intensification and WCB strength. Hereby, cyclone intensification is quantified by the normalized maximum 24-h central sea level pressure deepening and WCB strength by the WCB air mass associated with the cyclone's 24-h period of strongest deepening. Explosively intensifying cyclones typically have strong WCBs and pronounced WCB-related PV production in the cyclone center; they are associated with a WCB of type W2, which ascends close to the cyclone center. Cyclones with similar WCB strength but weak intensification are either diabatic Rossby waves, which do not interact with an upper-level disturbance, or cyclones where much of the WCB-related PV production occurs far from the cyclone center and thereby does not contribute strongly to cyclone deepening (WCB of type W1, which ascends mainly along the cold front). The category of explosively intensifying cyclones with weak WCBs is inhomogeneous but often characterized by a very low tropopause or latent heating independent of WCBs. These findings reveal that (i) diabatic PV production in WCBs is essential for the intensification of many explosive cyclones, (ii) the importance of WCBs for cyclone development strongly depends on the location of the PV production relative to the cyclone center, and (iii) a minority of explosive cyclones is not associated with WCBs.
\end{abstract}

\section{Introduction}

Many studies have shown that moist diabatic processes play an important role for the evolution of extratropical cyclones [see, e.g., the review by Uccellini (1990)]. Particularly, several case studies have revealed a significant contribution of latent heating to the intensification of explosively deepening cyclones (e.g., Reed et al. 1992; Wernli et al. 2002; Ludwig et al. 2014). Theoretical studies confirmed the importance of latent heating for cyclone development, revealing an increased intensification rate and structural changes in the presence of moisture (e.g., Mak 1982; Emanuel et al. 1987). The majority of these

Supplemental information related to this paper is available at the Journals Online website: http://dx.doi.org/10.1175/JAS-D-150302.s1.

Corresponding author address: Hanin Binder, Institute for Atmospheric and Climate Science, ETH Zürich, Universitätstrasse 16, CH-8092 Zurich, Switzerland.

E-mail: hanin.binder@env.ethz.ch studies adopted a potential vorticity (PV) perspective (Hoskins et al. 1985), where cyclone development is described by the interaction of an upper-level positive PV anomaly, a surface thermal anomaly, and a diabatically produced low-level positive PV anomaly. In the mature stage of a cyclone, the three anomalies can become vertically aligned to form a so-called PV towera column of anomalously high PV values spanning the troposphere and inducing a strong cyclonic circulation (Hoskins 1990; Rossa et al. 2000; Badger and Hoskins 2001). The diabatically produced low-level PV anomaly can significantly enhance the low-level circulation in cyclones and thereby contribute to their intensification (Davis and Emanuel 1991; Stoelinga 1996). It is also known that intense diabatic heating and low-level PV production in extratropical cyclones occurs in the warm conveyor belt (WCB; e.g., Wernli and Davies 1997). In this study we investigate whether these diabatically produced positive PV anomalies in WCBs affect cyclone intensification-that is, whether they become involved in the formation of PV towers in the center of cyclones. The following paragraphs provide more 
detailed information on theoretical studies on moist baroclinic instability, diabatic processes in real cyclones, and WCBs.

\section{a. Moist baroclinic instability}

Theoretical studies of moist baroclinic waves using linear and nonlinear models and different latent heating parameterizations have demonstrated that diabatic processes increase the growth rate and lead to a contraction of the region of ascent (Mak 1982; Emanuel et al. 1987; Whitaker and Davis 1994). An increase in moisture results in an enhanced cyclone intensification rate, a decrease in the minimum central pressure, and an increase in precipitation and extreme surface winds (Booth et al. 2013).

De Vries et al. (2010) developed a theoretical framework to describe the evolution of baroclinic waves in the presence of moisture. In this framework diabatic PV production is parameterized in terms of vertical motion, and PV anomalies are linearly partitioned into dry and moist components, which can interact with each other by their induced meridional and vertical velocities. Four unstable interactions have been identified between moist and dry waves in different layers, ranging from the classical dry instability (Eady 1949) to fully moist instability, with two intermediate types resulting from the interaction between a moist and a dry wave [see Cohen and Boos (2016) for a detailed review]. Hence, in three out of the four categories diabatic processes are crucial, but their interaction with the rest of the dynamics is different in each case.

\section{b. Diabatic processes in real cyclones}

The importance of moist processes for cyclone intensification has been pointed out in numerous case studies. Examples of strongly diabatically influenced, explosively intensifying cyclones include the Queen Elisabeth II storm in 1978 (Anthes et al. 1983; Gyakum 1983a,b), the Presidents' Day storm in 1979 (Bosart 1981; Atlas 1987; Whitaker et al. 1988), the Scamp storm in 1987 (Reed et al. 1992; Stoelinga 1996), Lothar in 1999 (Wernli et al. 2002; Rivière et al. 2010), and, more recently, Xynthia in 2010 (Fink et al. 2012; Liberato et al. 2013; Ludwig et al. 2014). In their mature stage, most of these cyclones were associated with a pronounced PV tower, with the low-level positive PV anomaly resulting from intense condensational PV production. In a climatological study, Čampa and Wernli (2012) showed that the amplitude of the upper-level, low-level, and surface positive $\mathrm{PV}$ anomalies tend to be stronger in intense than in weak cyclones. In the eastern North Atlantic, Dacre and Gray (2013) found a significant sensitivity of cyclone intensity after $48 \mathrm{~h}$ to the presence of a diabatically produced midlevel PV anomaly at the initial time. They suggested the PV anomaly to be related to diabatic processes within the WCB-however, without explicitly identifying the WCB by means of strongly ascending trajectories.

Two special categories of cyclones with an important contribution from low-level latent heating are type $\mathrm{C}$ cyclones (Deveson et al. 2002; Plant et al. 2003; Ahmadi-Givi et al. 2004) and diabatic Rossby waves (DRWs; Parker and Thorpe 1995; Boettcher and Wernli 2011, 2013). Type $\mathrm{C}$ cyclones are characterized by an interaction between an upper-level dry and a diabatically generated low-level PV anomaly, while the surface thermal anomaly plays a minor role for development. DRWs are low-level positive PV anomalies located in a moist, baroclinic environment, sufficiently distant from an upper-level disturbance such that coupling does not occur. They propagate rapidly along the baroclinic zone by continuous regeneration of the DRW downstream of its original position through diabatic processes.

In addition to the role of latent heating for cyclone intensification, a few publications suggested that moist processes can also influence the track of extratropical cyclones. In idealized cyclones, Coronel et al. (2015) found a faster northeastward and cross-jet motion in the presence of moisture, corroborating earlier findings of idealized studies (Mak 1982) and simulations of real cyclones (e.g., Davis et al. 1993). They explained the eastward motion by the diabatically produced low-level PV anomaly as in the case of DRWs and the northward motion by nonlinear advection by the upper-level positive and diabatically enhanced negative PV anomalies forming up- and downstream, respectively. The importance of the upper-level PV and diabatic heating for the cyclone's poleward propagation was confirmed by Tamarin and Kaspi (2016), who performed a detailed PV tendency analysis for cyclones in an idealized GCM.

\section{c. Warm conveyor belts}

The WCB plays a key role when investigating diabatic processes from a Lagrangian perspective. It is a coherent warm and moist airstream, which originates in the boundary layer of the cyclone's warm sector and ascends rapidly to the upper troposphere while moving toward polar regions (e.g., Harrold 1973; Browning et al. 1973; Carlson 1980). The WCB is the primary cloud- and precipitation-generating flow in extratropical cyclones (Browning 1990), and it plays a crucial role for total and extreme precipitation events in many regions of the extratropics (Pfahl et al. 2014). In a detailed case study on microphysical processes along a WCB, Joos and Wernli (2012) showed that several microphysical processes can modify PV, in particular condensation of water vapor at 
low levels, and depositional growth of snow at upper levels. In the Northern Hemisphere, WCBs are more frequent in winter than in summer, with two preferential ascending regions in the western North Atlantic and North Pacific (Eckhardt et al. 2004; Madonna et al. 2014).

In many descriptions the WCB is divided into two branches (Young et al. 1987; Browning and Roberts 1994; Browning 1999; Martínez-Alvarado et al. 2014). The primary branch, W1, travels along the cold front, and depending on the movement of the air relative to the cold front it can be distinguished between rearward-sloping ascent above the cold front and forward-sloping ascent above the warm front (cf. Browning 1990). The secondary branch, W2, approaches the cyclone center and rises above the bent-back front into the cloud head. In a case study of an extratropical cyclone, Wernli (1997) identified both W1 WCB trajectories rising at the cold and warm fronts, respectively, and a W2 flow ascending in the close vicinity of the cyclone center. A WCB of type W2 has also been identified in idealized experiments of moist baroclinic waves (Schemm et al. 2013).

As mentioned above, the intense WCB-related clouddiabatic processes produce a strong positive PV anomaly in the lower and middle troposphere. At upper levels diabatic PV destruction leads to low PV values in the WCB outflow. These produce significant negative PV anomalies in the tropopause region, which can interact with the extratropical waveguide and thereby substantially influence the downstream flow (e.g., Wernli 1997; Pomroy and Thorpe 2000; Massacand et al. 2001; Ahmadi-Givi et al. 2004; Grams et al. 2011; Methven 2015).

In this study we focus on the low-level positive PV anomaly that occurs during the early phase of the WCB ascent, and its influence on the associated cyclone. Very little is known about the location of strongest WCB-related ascent and PV production relative to the cyclone center and whether these positive PV anomalies contribute to cyclone intensification. In addition, no studies are available on the relative importance of the W1 and W2 types of WCBs for cyclone development.

\section{d. Objectives and structure of this study}

The goal of this study is to quantify the role of WCBs and their associated positive PV anomalies for the intensification of a large set of cyclones in Northern Hemisphere (NH) winter. To this end, cyclone intensification will be measured as the normalized maximum sea level pressure (SLP) deepening over $24 \mathrm{~h}$ (Sanders and Gyakum 1980), and WCB strength will be quantified as the number and mass of the WCB trajectories associated with the cyclone at low levels during its strongest intensification (see sections $2 \mathrm{~d}$ and $2 \mathrm{e}$ ). An illustrative case study and detailed climatological analyses will be used to address the following questions:

1) For a climatological set of cyclones, is there a correlation between cyclone intensification and the strength of the associated WCB?

2) What is the structure and evolution of strongly deepening cyclones with an intense WCB, and where do the WCB-related positive $\mathrm{PV}$ anomalies occur relative to the cyclone center?

3) How do strongly deepening cyclones with an intense WCB differ in terms of structure and evolution from (i) weakly deepening cyclones with an intense WCB and (ii) strongly deepening cyclones with a weak WCB?

In the supplemental material it is assessed how sensitive the answers to these questions are for different measures of cyclone intensification. For the climatological analyses, we will use composite techniques, which have proven to be insightful to examine the common characteristics of particular types of cyclones (e.g., Field and Wood 2007; Bengtsson et al. 2009; Catto et al. 2010; Dacre et al. 2012).

The structure of the remainder of this paper is as follows. Section 2 describes the methods used in this study. In section $3 a$ the statistical connection between cyclone intensification and WCB strength is discussed, and based on these measures three different cyclone categories are defined. Section $3 b$ presents the spatial distribution of the three categories. The category of explosively intensifying cyclones with a strong WCB is discussed in section 4, the category of weak cyclones with a strong WCB in section 5, and the category of explosively intensifying cyclones with a weak WCB in section 6 . Section 7 provides a summary of the results and the main conclusions.

\section{Data and methods}

\section{a. Data}

This study is based on the ERA-Interim dataset from the European Centre for Medium-Range Weather Forecasts (Simmons et al. 2007; Dee et al. 2011). The analysis is confined to the NH winter (December-February) for the period 1979-2014. ERA-Interim data are available at a spectral resolution of T255 on 60 vertical levels and at a temporal resolution of $6 \mathrm{~h}$. The original fields are interpolated onto a $1^{\circ} \times 1^{\circ}$ longitude-latitude grid. From the primary data, potential vorticity, potential temperature $\theta$, the horizontal wind velocity, and the upper-level forced quasigeostrophic (QG) vertical motion are calculated as secondary variables. The QG vertical motion is calculated with the diagnostic of Clough et al. (1996). As in Boettcher 
and Wernli (2011, 2013), the vertical motion induced by the upper levels, defined as the layer between 500 and $100 \mathrm{hPa}$, is evaluated at $700 \mathrm{hPa}$.

\section{b. WCB identification}

The study makes use of the WCB climatology provided by Madonna et al. (2014). It is based on trajectory calculations with the Lagrangian Analysis Tool (LAGRANTO; Wernli and Davies 1997; Sprenger and Wernli 2015) and the application of a Lagrangian selection criterion that accounts for the strong ascent of WCBs (Wernli and Davies 1997). Forward trajectories are started globally, every $6 \mathrm{~h}$ from an equidistant grid with $\Delta x=$ $80-\mathrm{km}$ horizontal and $\Delta p=20$-hPa vertical resolution in the lower troposphere between 1050 and $790 \mathrm{hPa}$. WCB trajectories are then identified as air parcels that ascend more than $600 \mathrm{hPa}$ within $48 \mathrm{~h}$ from the boundary layer to the upper troposphere. Furthermore, in order to exclude deep convective systems, the horizontal position of the WCB trajectory must be collocated with a surface cyclone for at least one 6-hourly time step during the ascent [see Madonna et al. (2014) for details]. The trajectory data consist of the horizontal position, pressure, and the evolution of different physical parameters along the WCB path every $6 \mathrm{~h}$ during the 2-day ascent phase.

\section{c. Cyclone identification and tracking}

The climatology of extratropical cyclones is based on a slightly modified version of the procedure developed by Wernli and Schwierz (2006); the same as used in Madonna et al. (2014). It consists of an identification algorithm, which yields cyclone areas every $6 \mathrm{~h}$, and a separate tracking algorithm. A surface cyclone is identified as the two-dimensional area surrounding one or several local SLP minima enclosed by the outermost closed SLP contour, with the maximum length of this contour restricted to $7500 \mathrm{~km}$. The enclosed area is regarded as the cyclone area. The tracking algorithm connects cyclone centers by searching the most likely continuation for each SLP minimum among the identified minima $6 \mathrm{~h}$ later.

While the tracking algorithm mostly performs well, in some cases long-lived systems are erroneously split into shorter-lived systems. In addition to very short tracks, this can result in unrealistic cyclone life cycles-for instance, cyclones with a very low SLP minimum and a large area already at the beginning of their tracks. To retain only tracks with a realistic and well-defined cyclone life cycle, in the current analysis it is specified that (i) the track duration is at least $48 \mathrm{~h}$ and (ii) at the first time step of the track the pressure difference between the outermost closed SLP contour and the SLP minimum is less than $5 \mathrm{hPa}$. This threshold value of $5 \mathrm{hPa}$ has been subjectively chosen by analyzing a number of critical tracks. Of course not all unrealistic cases can be filtered out with these requirements, while others are erroneously excluded, but nevertheless a detailed investigation of many cases showed that the large majority of the retained tracks has a well-defined and realistic cyclone life cycle.

In addition to the two filters mentioned above, tropical cyclones are excluded from the analysis by considering only tracks located north of $25^{\circ} \mathrm{N}$ at least for one 24-h interval. In total, over the 36-yr study period 5069 extratropical cyclones are found that meet these criteria.

\section{d. Attribution of WCBs to cyclones}

To investigate the interaction between cyclone intensification and WCBs, every WCB trajectory is attributed to a cyclone. As described above, in our climatology it is requested that every WCB trajectory matches with a surface cyclone area at least once during the 2-day ascent. Here use is made of this criterion by identifying for every cyclone, during the entire cyclone life cycle, all WCB trajectories that overlap with the horizontal position of the cyclone area. Not all cyclones are associated with WCB trajectories, but-because of the matching criterion set by Madonna et al. (2014) — every WCB trajectory can be attributed to a cyclone.

In some cases a WCB trajectory matches with more than one cyclone during the $48 \mathrm{~h}$. Such a double counting can occur, for instance, when a WCB trajectory matches with a first cyclone during the ascent, and with a second cyclone when the WCB outflow later moves over the area encompassed by another cyclone. Since the focus of this study is on the role of the low-level PV produced during the WCB ascent, in cases of several matches at different stages of the 2-day ascent, a WCB trajectory is attributed only to the first cyclone. By assigning every WCB trajectory to one cyclone track, we obtain for every cyclone the number of associated WCB trajectories, as well as their position and physical properties along the entire cyclone life cycle.

\section{e. Measures for cyclone intensification and WCB strength}

Following the approach of Sanders and Gyakum (1980), cyclone intensification is quantified in units of Bergeron, with

$$
\Delta \mathrm{SLP}_{B}=\frac{\Delta \mathrm{SLP}}{24} \frac{\sin \left(60^{\circ}\right)}{\sin (\phi)}
$$

Here, $\triangle$ SLP is the change of the minimum SLP (hPa) over a 24-h interval along the track and $\phi$ is the mean latitude of the cyclone center during this interval. The 
cyclone deepening rate $\left(\Delta \mathrm{SLP}_{B, \max }\right)$ is then defined as the maximum value of $\Delta \mathrm{SLP}_{B}$ of all 24-h intervals along the track. In the present study, only 24 -h intervals are considered in which the cyclone is located entirely poleward of $25^{\circ}$ latitude. After Sanders and Gyakum (1980), cyclones with a deepening rate of at least 1 Bergeron are considered to be intensifying explosively as so-called bombs. This corresponds to a deepening rate of $24 \mathrm{hPa}$ in $24 \mathrm{~h}$ at $60^{\circ} \mathrm{N}$. Alternative cyclone intensification measures that take into account the climatological pressure distribution or are based on relative vorticity, and their relationship with WCBs, are discussed in the supplemental material.

The WCB strength associated with a certain cyclone is measured by counting the number of WCB trajectories that are attributed to this cyclone and located at low levels (pressure $>500 \mathrm{hPa}$ ) sometime during the $24-\mathrm{h}$ interval of strongest intensification. The trajectories can in principle be outside the cyclone area during this $24-\mathrm{h}$ period, as long as they match with the cyclone at least once during their 2-day ascent. Because of the equidistant starting grid of the WCB trajectories (see section $2 b)$ every WCB trajectory represents the same amount of air mass [i.e., $\Delta m \approx(1 / g)(\Delta x)^{2} \Delta p \approx 1.3 \times 10^{12} \mathrm{~kg}$, with $\left.g=9.81 \mathrm{~m} \mathrm{~s}^{-2}\right]$, and the total WCB air mass at low levels associated with a cyclone is obtained by multiplying the number of WCB trajectories by $\Delta m$.

To evaluate the statistical relationship between cyclone intensification and WCB strength, the Spearman rank correlation coefficient is used (Spearman 1904). It is a nonparametric measure for the monotonic relationship between two variables.

\section{Connection between cyclone intensification and WCB strength}

\section{a. Statistical relationship between cyclone intensification and WCB strength}

Figure 1 shows for all $\sim 5000$ cyclone tracks a twodimensional histogram of the statistical relationship between the WCB strength and the cyclone deepening rate $\left(\triangle \mathrm{SLP}_{B, \max }\right)$ and, separately, their one-dimensional histograms. The distributions of WCB strength and cyclone intensification are positively skewed toward intense WCBs and strong cyclone intensification rate, respectively. The latter is in accordance with the statistical analyses by Roebber (1984) and Gyakum et al. (1989).

The red and light green colors in the two-dimensional histogram reveal that many cyclones are associated with a weak deepening and few WCB trajectories. Effectively, $45 \%$ of all cyclones are not associated with any WCB trajectory (of which $98.5 \%$ have a deepening rate of less than 1 Bergeron), which is in good qualitative agreement with the findings of Eckhardt et al. (2004). They mainly occur in regions of low climatological WCB frequency (Eckhardt et al. 2004; Madonna et al. 2014), in particular at high latitudes, in the Mediterranean region and over the continents (not shown). The dark green and blue colors in Fig. 1 indicate a tendency that more intense cyclones are associated with stronger WCBs. This is confirmed by the Spearman rank correlation coefficient of 0.68 , which implies a moderate to strong positive correlation between cyclone intensification and the strength of the associated WCB. In numbers, the average deepening rate increases from 0.28 Bergeron for cyclones with less than $50 \mathrm{WCB}$ trajectories, to 0.8 Bergeron for cyclones with a WCB trajectory number between 50 and 1500 , and to 1.35 Bergeron for cyclones with more than 1500 WCB trajectories. However, a large scatter is apparent with some cyclones intensifying strongly without any WCB contribution, and others having a strong WCB but intensifying only weakly.

The position of some prominent winter storms is marked by letters in the phase space in Fig. 1. They all intensified explosively, and most of them were associated with a strong WCB. Among those with a particularly strong WCB are the storms Martin (Ulbrich et al. 2001) and Xynthia (Liberato et al. 2013), which caused major damage in western and central Europe, as well as several memorable storms along and off the U.S. East Coast, like the Presidents' Day snowstorm (Bosart 1981; Atlas 1987; Whitaker et al. 1988), the snowstorms of 4-5 February 1995 (Nicosia and Grumm 1999) and 24-25 January 2000 (Zhang et al. 2002), and the devastating windstorm Scamp (Reed et al. 1992; Stoelinga 1996).

The winter storms Lothar and Klaus had a weaker WCB, although they have been identified as strongly diabatically driven cyclones (Wernli et al. 2002; Fink et al. 2012). In comparison to most of the abovementioned storms, which reached a considerable size during explosive intensification, Lothar and Klaus both remained relatively small-scale storms, and their weak WCB strength is therefore related to the small size of these cyclones. As a test, we performed an additional analysis, where the WCB strength is measured by the number of WCB trajectories normalized by the cyclone area. Using this measure, Klaus and Lothar both attain WCB strength at the high end of the distribution of all cyclones. On the other hand, for large cyclones such a normalization resulted in a weak WCB strength when the WCB trajectories were concentrated in a small area around the cyclone center. However, except for these two subgroups the distribution of the cyclones in the phase-space diagram 

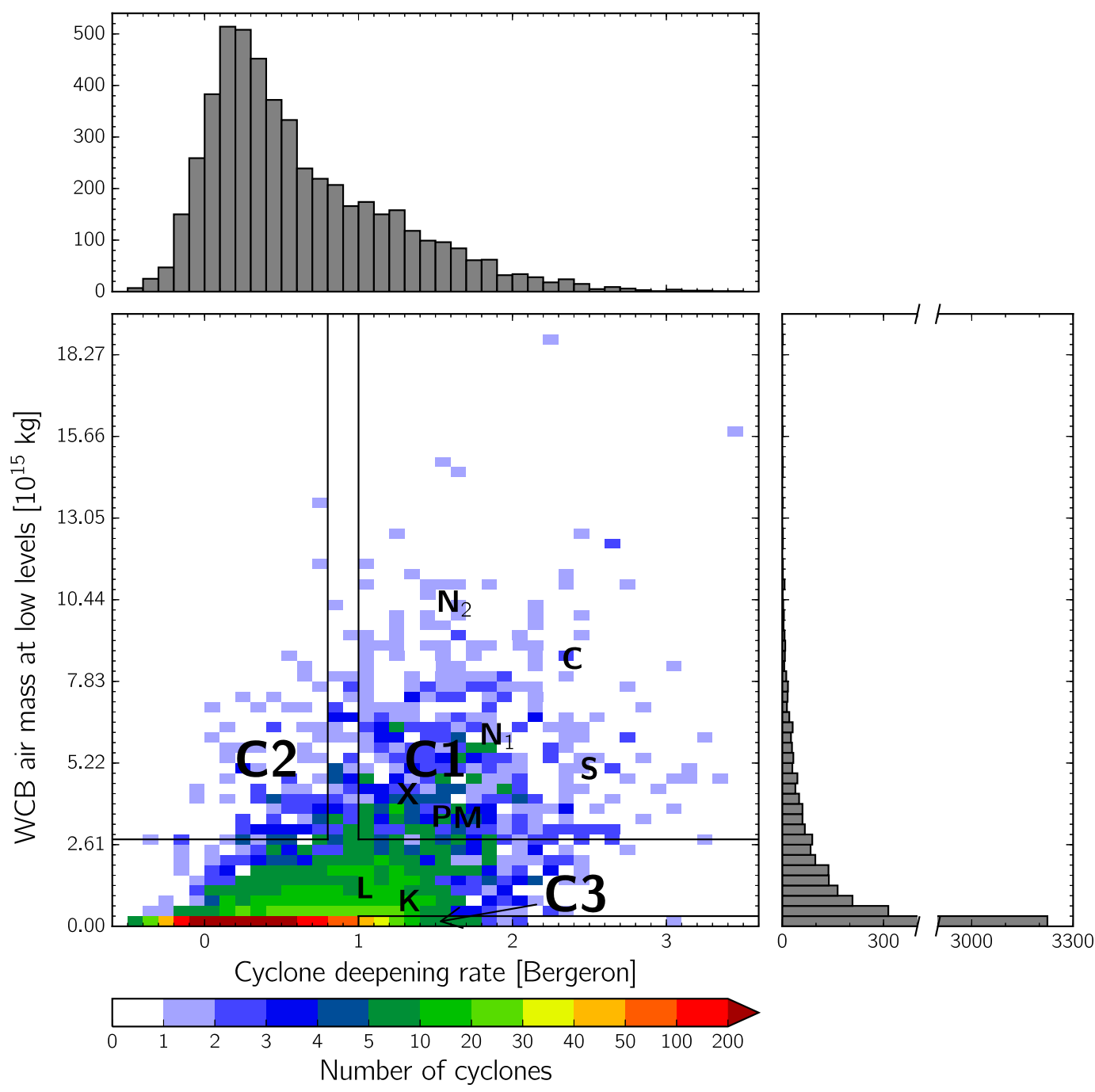

FIG. 1. (bottom left) Two-dimensional histogram showing for every NH winter cyclone the deepening rate $\left(\Delta \mathrm{SLP}_{B, \max }\right)($ Bergeron; bin width $=0.1$ Bergeron $)$ and the associated WCB strength, expressed by the mass of the WCB trajectories at low levels integrated over the 24 -h period of strongest pressure deepening (bin width $\approx$ $0.33 \times 10^{15} \mathrm{~kg}$, corresponding to $250 \mathrm{WCB}$ trajectories). Colors indicate the number of cyclones in a specific bin. The corresponding one-dimensional histograms are shown for (top) cyclone deepening and (bottom right) WCB strength. The total number of cyclones is 5069. The Spearman rank correlation coefficient between cyclone intensification and WCB strength is 0.68 . The boundaries of category $\mathrm{C} 1, \mathrm{C} 2$, and $\mathrm{C} 3$ are marked by the black lines, and the letters indicate the position of specific cyclones: " $C$ " $-\mathrm{C} 1$ case study discussed in section 4a; "K"-storm Klaus; "L"- -storm Lothar; " $\mathrm{M}$ "- -storm Martin; " $\mathrm{N}_{1}$ " and " $\mathrm{N}_{2}$ " - - nor'easter snowstorms in February 1995 and January 2000, respectively; "P"'-Presidents' Day cyclone; "S"-Scamp storm; and "X"storm Xynthia.

remained very similar as in Fig. 1, indicating that for most cyclones it is meaningful to measure WCB strength in absolute terms - that is, not normalized by the cyclone area.

To understand whether and how WCBs can influence cyclone intensity, in the following the structure and evolution of different cyclone categories, defined in the phase space shown in Fig. 1, is investigated in detail. The category boundaries of the $\mathrm{C} 1$ cyclones are defined by choosing from the explosively intensifying cyclones (deepening rate of at least 1 Bergeron) the 500 cases with maximum WCB strength. This yields a lower threshold of $2.78 \times 10^{15} \mathrm{~kg}$ for the $\mathrm{WCB}$ strength (equivalent to $2130 \mathrm{WCB}$ trajectories). As evident in Fig. 1, many of the above discussed wellknown storms are in category $\mathrm{C} 1$. C2 cyclones $(n=$ 101) have a similar WCB strength as $\mathrm{C} 1$ (at least $2.78 \times 10^{15} \mathrm{~kg}$ ) but a weak deepening rate of less than 


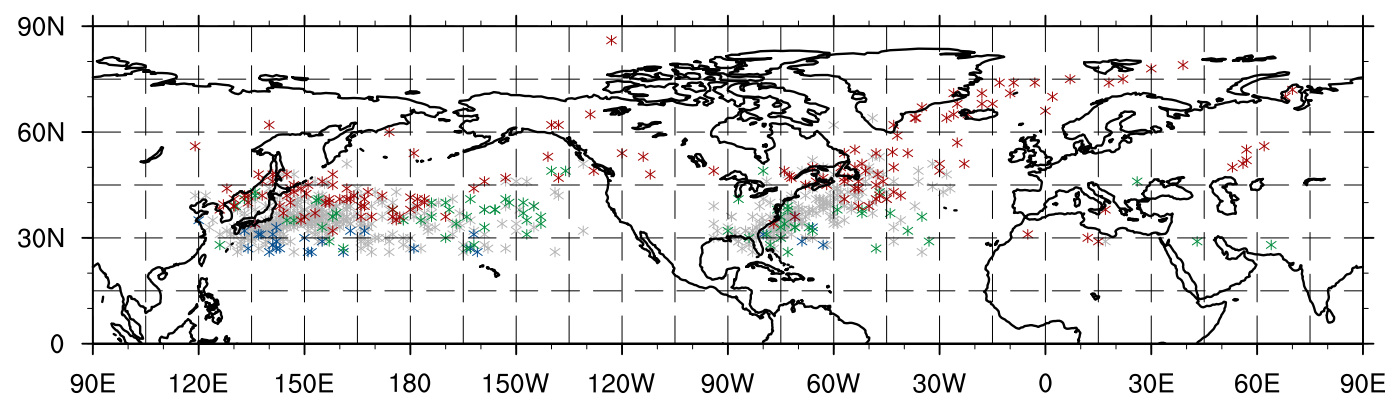

FIG. 2. Spatial distribution of cyclones at the beginning of their 24-h period of maximum intensification. C1 cyclones are shown by gray labels $(n=500), \mathrm{C} 2$ cyclones are blue for subtype C2a $(n=29)$ and green for subtype $\mathrm{C} 2 \mathrm{~b}(n=72)$, and C3 cyclones are red $(n=154)$.

0.8 Bergeron. Finally, C3 cyclones $(n=154)$ are defined as explosively intensifying cyclones with a weak WCB with a maximum of $0.33 \times 10^{15} \mathrm{~kg}$ (equivalent to 250 WCB trajectories; Fig. 1). Because of the positive correlation between cyclone intensification and WCB strength, on average the $\mathrm{C} 1$ cyclones have a stronger WCB than $\mathrm{C} 2$ (on average $5.37 \times 10^{15} \mathrm{~kg}$ compared to $4.50 \times 10^{15} \mathrm{~kg}$ in C2). Likewise, the average Bergeron value is larger in $\mathrm{C} 1$ (1.67 Bergeron) than in C3 (1.27 Bergeron).

While for $\mathrm{C} 1$ and $\mathrm{C} 3$ the categories are analyzed as a whole, for $\mathrm{C} 2$ two subtypes are distinguished: $\mathrm{C} 2 \mathrm{a}$ cyclones $(n=29)$ do not interact with a tropopause disturbance (defined by the 2-PVU ${ }^{1}$ contour on $315 \mathrm{~K}$ ) during the entire 24 -h period of strongest intensification, while $\mathrm{C} 2 \mathrm{~b}(n=72)$ are associated with at least a weak tropopause interaction. The assignment to the two subtypes is based on manual analysis of the individual cyclones. As shown in the supplemental material, the attribution of the cyclones to the three categories and their mean properties are fairly robust to the measure used to define cyclone intensification.

\section{b. Spatial distribution of the cyclones in $C 1, C 2$, and $C 3$}

Figure 2 shows the spatial distribution of the cyclones in the different categories at the beginning of their strongest deepening (referred to in the following as $t=0 \mathrm{~h}$, while the middle and the end of the 24 -h period of strongest SLP deepening will be referred to as $t=12 \mathrm{~h}$ and $t=24 \mathrm{~h}$, respectively). The majority of the $\mathrm{C} 1$ cyclones is located between $25^{\circ}$ and $50^{\circ} \mathrm{N}$ (mean latitude of $36^{\circ} \mathrm{N}$ ) in the western and central ocean basins in regions of high climatological WCB frequency [Fig. 4 in Madonna et al. (2014)].

The majority of the $\mathrm{C} 2$ cyclones also occurs in regions of high climatological WCB frequency (Fig. 2). The C2a

\footnotetext{
${ }^{1}$ Potential vorticity unit; $1 \mathrm{PVU}=10^{-6} \mathrm{~m}^{2} \mathrm{~s}^{-1} \mathrm{~K} \mathrm{~kg}^{-1}$.
}

cases are located relatively far south (mean latitude $<30^{\circ} \mathrm{N}$ at $t=0 \mathrm{~h}$ ), and the $\mathrm{C} 2 \mathrm{~b}$ cyclones are slightly farther poleward (mean latitude of $36^{\circ} \mathrm{N}$, as for $\mathrm{C} 1$ ).

In contrast to $\mathrm{C} 1$ and $\mathrm{C} 2$, many $\mathrm{C} 3$ cyclones occur at high latitudes or over the continents (Fig. 2) - both regions of low climatological WCB frequency. Additionally, a large number of $\mathrm{C} 3$ cyclones are located in the western and central ocean basins, although at more poleward latitudes than $\mathrm{C} 1$ and $\mathrm{C} 2$ (the mean latitude of all $\mathrm{C} 3 \mathrm{cy}$ clones is $49^{\circ} \mathrm{N}$ ). Given their widespread occurrence, it is unlikely that $\mathrm{C} 3$ cyclones share a common evolution pattern (see later).

In the following the three categories are analyzed with the help of composites that are centered at the position of the SLP minimum. C1 cyclones are discussed first and in greatest detail in the next section, and their composites are shown at the beginning, in the middle, and at the end of the 24-h period of strongest intensification. The spatial structure of the C2 and C3 cyclones does not change considerably during their intensification. Therefore, for these categories only the composites at $t=12 \mathrm{~h}$ are discussed. Their composites at $t=0 \mathrm{~h}$ and $t=24 \mathrm{~h}$ are shown in the supplemental material. Additionally, in the supplemental material the temporal evolution of various parameters is compared for the three categories.

To identify a potential issue with conflation of basinspecific cyclone dynamics when compositing both Atlantic and Pacific cyclones, in each category separate composites have been created for the two regions (not shown). They showed that the overall structure and the main characteristics of the cyclones are very similar in both regions. In addition, it has been examined whether there is an issue in using different sample sizes in $\mathrm{C} 1(n=500)$ and C2a $(n=29)$ by comparing the composites of 29 randomly selected $\mathrm{C} 1$ cyclones (not shown) to the entire $\mathrm{C} 1$ category. The structure of the subsample is very similar to the entire category, which indicates that a relatively small sample 
of 29 cyclones is sufficient to capture the main features of a category.

\section{Category C1-Explosively intensifying cyclones with strong WCBs}

Before proceeding to the $\mathrm{C} 1$ composite analysis, a case study is described that represents the main characteristics of the $\mathrm{C} 1$ cyclones.

\section{a. Case study}

During the period 6-11 January 1990, an intense extratropical cyclone with a strong WCB developed over the North Atlantic. The system underwent an explosive deepening of $44 \mathrm{hPa}$ between 1800 UTC 6 January and 1800 UTC 7 January (corresponding to 2.4 Bergeron) and was associated with a WCB strength of $8.49 \times 10^{15} \mathrm{~kg}$ (see Fig. 1, label "C"). Overall, the minimum SLP dropped by almost $80 \mathrm{hPa}$ in the course of $54 \mathrm{~h}$.

The cyclone formed in the western North Atlantic (near $35^{\circ} \mathrm{N}, 74^{\circ} \mathrm{E}$ ) at 1200 UTC 6 January south of an intense baroclinic zone. The system reached a minimum SLP of $1006 \mathrm{hPa} 6 \mathrm{~h}$ later (Fig. 3a). At upper levels, a weak disturbance is located northwest of the developing system (Fig. 3a). Northeast of the cyclone, 250-hPa wind speeds of more than $90 \mathrm{~m} \mathrm{~s}^{-1}$ are present (Fig. 3b).

A strong WCB is associated with the cyclone. The WCB inflow at 1800 UTC 6 January occurs near the cyclone center and to the east along the baroclinic zone (Fig. 4a). Figure 3a shows the position and mean PV values of all gridded WCB air parcels that are located at low levels at 1800 UTC 6 January-that is, not only of the trajectories starting at that time step (Fig. 4a), but also of all WCB air parcels associated with the cyclone that started ascending at earlier time steps and are still in the lower troposphere. The PV values in Fig. 3a denote mean values over all trajectories at that grid point located somewhere in the vertical column between 1000 and $500 \mathrm{hPa}$. Slightly to the west of the cyclone center, the values are highest (more than 0.7 PVU; Fig. 3a) and related to midlevel air parcels, as evident in the west-east-oriented vertical section across the cyclone center (Fig. 5a). Another weak positive PV anomaly and coinciding WCB air parcels are present in the cyclone center at low levels (Fig. 5a). To the east, WCB trajectories with relatively low PV values of less than 0.5 PVU occur along the baroclinic zone (Figs. 3a,b). They correspond to boundary layer trajectories (Fig. 5a) and, hence, to the WCB inflow seen in Fig. 4a. WCB intersections with the 315-K isentrope to the west of the cyclone center (Fig. 3a) belong at that time to midlevel rather than upper-level air parcels (Fig. 5a), which is due to the southerly position of the cyclone and accordingly the low altitude of the $315-\mathrm{K}$ isentrope.

As the cyclone propagates farther northeastward it strongly intensifies, reaching a minimum SLP of about $981 \mathrm{hPa} 12 \mathrm{~h}$ later at 0600 UTC 7 January (Fig. 3c). The cyclone is now located at the leading edge of an upperlevel trough (Fig. 3c) near the right entrance of the slightly weakened jet (Fig. 3d). At the surface, cold and warm fronts start to develop. In addition to the WCB trajectories that have started at earlier time steps (Fig. 4a), a new WCB inflow forms to the east of the cyclone (Fig. 4b). Low-level WCB air parcels are present in the cyclone center and along the fronts (Fig. 3c). Importantly, the highest mean PV of the WCB air parcels occurs near the cyclone center, with values of almost $2 \mathrm{PVU}$, pointing to strong $\mathrm{WCB}$ induced diabatic $\mathrm{PV}$ production. In the same region, a pronounced low-level $\mathrm{PV}$ maximum is visible both on $850 \mathrm{hPa}$ (Fig. 3d) and in the vertical section (Fig. 5b). A vortex with high PV values of more than 1 PVU has developed and extends from the surface up to about $450 \mathrm{hPa}$, with a maximum of more than $2 \mathrm{PVU}$ around $850 \mathrm{hPa}$. At the location of the vortex, a large number of WCB trajectories with high PV (cf. Fig. 3c) occur, corroborating that the pronounced PV anomaly has been formed by diabatic processes in the ascending WCB. To the west of the low-level vortex, a deep trough is present (Fig. 5b), which constitutes a favorable condition for the continuing explosive intensification of the storm.

The infrared satellite image shows cold cloud tops in the warm sector in the region of strongest ascent of the WCB (Fig. 6). Farther to the west, the motion of the trajectories along the cold front, which took place at earlier time steps as seen in Fig. 4a, manifests itself in an almost west-east-oriented cloud band extending from the U.S. East Coast toward the cyclone center, accompanied by a gradual increase of cloud-top height, and, most likely, embedded convection.

Minimum SLP amounts to $962 \mathrm{hPa} 12 \mathrm{~h}$ later (i.e., at the end of the explosive deepening) (Fig. 3e). The upper-level disturbance has developed into an intense LC2-type wave (Thorncroft et al. 1993) wrapping cyclonically around the low-PV air. WCB intersection points at upper levels suggest the presence of both cyclonically and anticyclonically turning air in the WCB outflow, coupled with strong ridge amplification. Intense low-level diabatic PV production by WCB trajectories still occurs along the fronts and in the cyclone center, with anomalously high mean PV values of more than 2 PVU slightly southwest of the cyclone center (Fig. 3e). The low-level PV anomaly has further intensified 

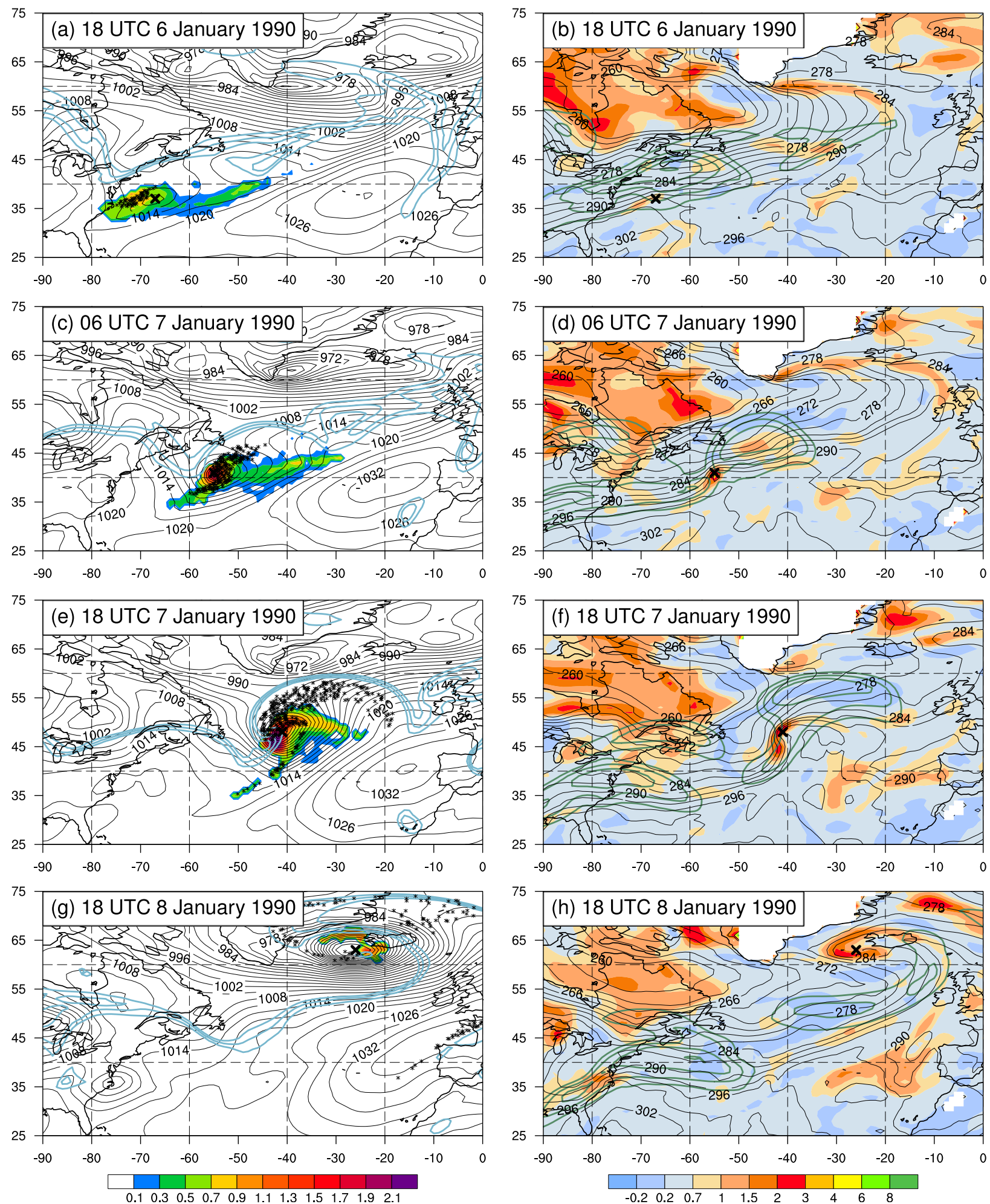

FIG. 3. Case study for category C1. Synoptic situation at (a),(b) 1800 UTC 6 Jan 1990, corresponding to $t=0 \mathrm{~h}$; (c),(d) $0600 \mathrm{UTC} 7 \mathrm{Jan}$, corresponding to $t=12 \mathrm{~h}$; (e),(f) 1800 UTC 7 Jan, corresponding to $t=24 \mathrm{~h}$; and (g),(h) $1800 \mathrm{UTC} 8 \mathrm{Jan}$. (left) Mean PV value of gridded WCB air parcels with pressure $>500 \mathrm{hPa}$ (PVU; shading), SLP (hPa; black contours every $3 \mathrm{hPa}$ ), $\mathrm{PV}$ on $315 \mathrm{~K}$ (blue contours for 2,3 , and $4 \mathrm{PVU}$ ), and intersection positions of WCB trajectories with the isentropic layer between 312.5 and $317.5 \mathrm{~K}$ (asterisks). (right) PV (PVU; shading) and potential temperature (black contours every $3 \mathrm{~K}$ ) at $850 \mathrm{hPa}$, and wind speed at $250 \mathrm{hPa}$ (green contours for 50, 60, 70, 80, and $\left.90 \mathrm{~m} \mathrm{~s}^{-1}\right)$. The black cross marks the position of the cyclone center. 

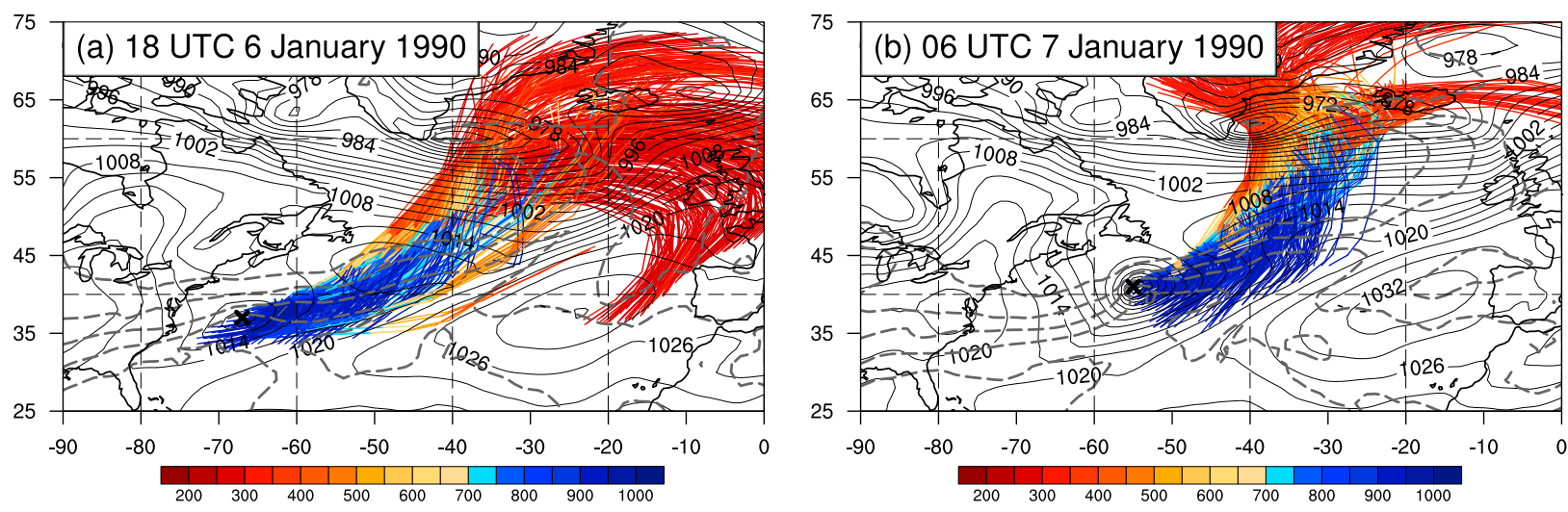

FIG. 4. Two-day WCB trajectories (colored by pressure; hPa) starting at (a) 1800 UTC 6 Jan 1990 , corresponding to $t=0 \mathrm{~h}$, and (b) 0600 UTC $7 \mathrm{Jan}$, corresponding to $t=12 \mathrm{~h}$, and SLP (contours every $3 \mathrm{hPa}$ ) and potential temperature at $850 \mathrm{hPa}$ (gray dashed contours for $\theta=280$, $285,290,295$, and $300 \mathrm{~K}$ ) at the start time of the trajectories. The black cross marks the position of the cyclone center.

(Figs. 3f and 5c), and above the low-level anomaly a narrow stratospheric intrusion is penetrating into the troposphere. Together they form an almost vertically aligned PV tower that induces a strong cyclonic circulation throughout the troposphere.
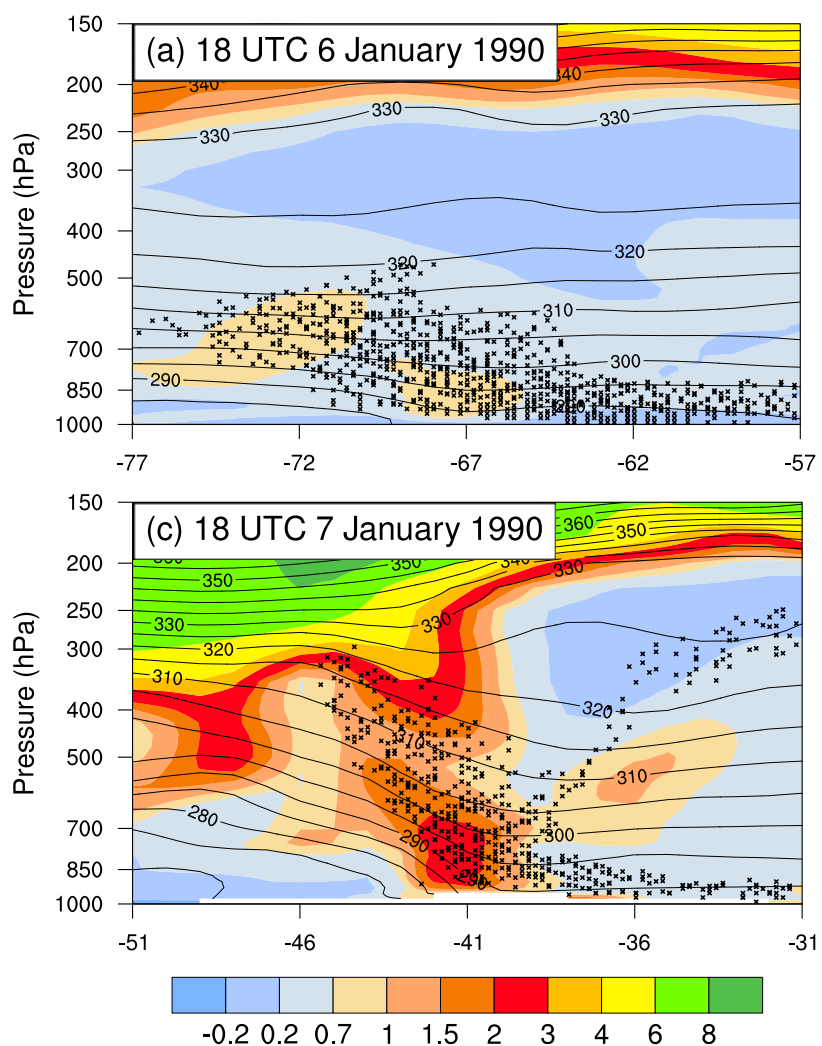

Over the next $12 \mathrm{~h}$ the pressure decreases at a similar rate, with continuous low-level diabatic $\mathrm{PV}$ production by the ascending WCB. At 0600 UTC 8 January the storm reaches its maximum intensity in terms of relative vertical vorticity at $850 \mathrm{hPa}$ (not shown), but the
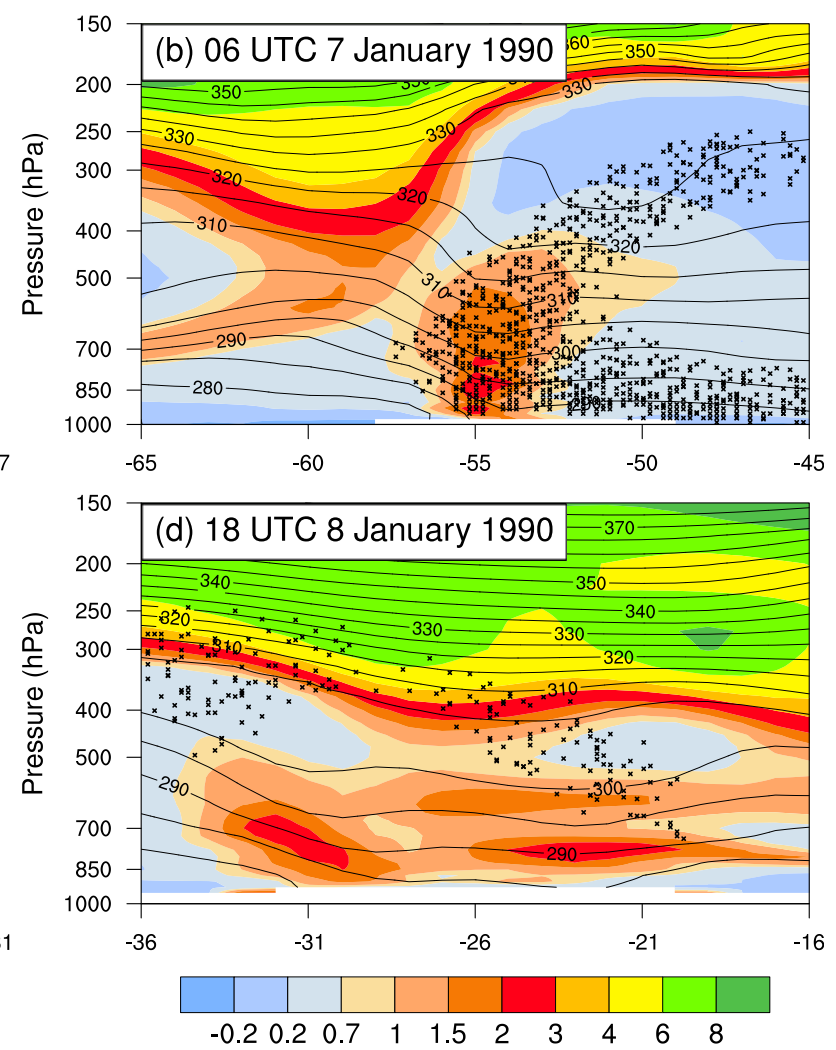

FIG. 5. West-east vertical cross sections through the cyclone center at (a) $1800 \mathrm{UTC} 6 \mathrm{Jan} 1990$, corresponding to $t=0 \mathrm{~h}$ (from $77^{\circ}$ to $57^{\circ} \mathrm{W}$ ); (b) $0600 \mathrm{UTC} 7 \mathrm{Jan}$, corresponding to $t=12 \mathrm{~h}$ (from $65^{\circ}$ to $45^{\circ} \mathrm{W}$ ); (c) $1800 \mathrm{UTC} 7 \mathrm{Jan}$, corresponding to $t=24 \mathrm{~h}$ (from $51^{\circ}$ to $31^{\circ} \mathrm{W}$ ); and (d) 1800 UTC 8 Jan (from $36^{\circ}$ to $16^{\circ} \mathrm{W}$ ). In each case the cyclone center is located in the middle of the displayed cross section. Shown are PV (PVU; shading), potential temperature (contours every $5 \mathrm{~K}$ ), and intersection positions of WCB trajectories with the cross section (black crosses). 


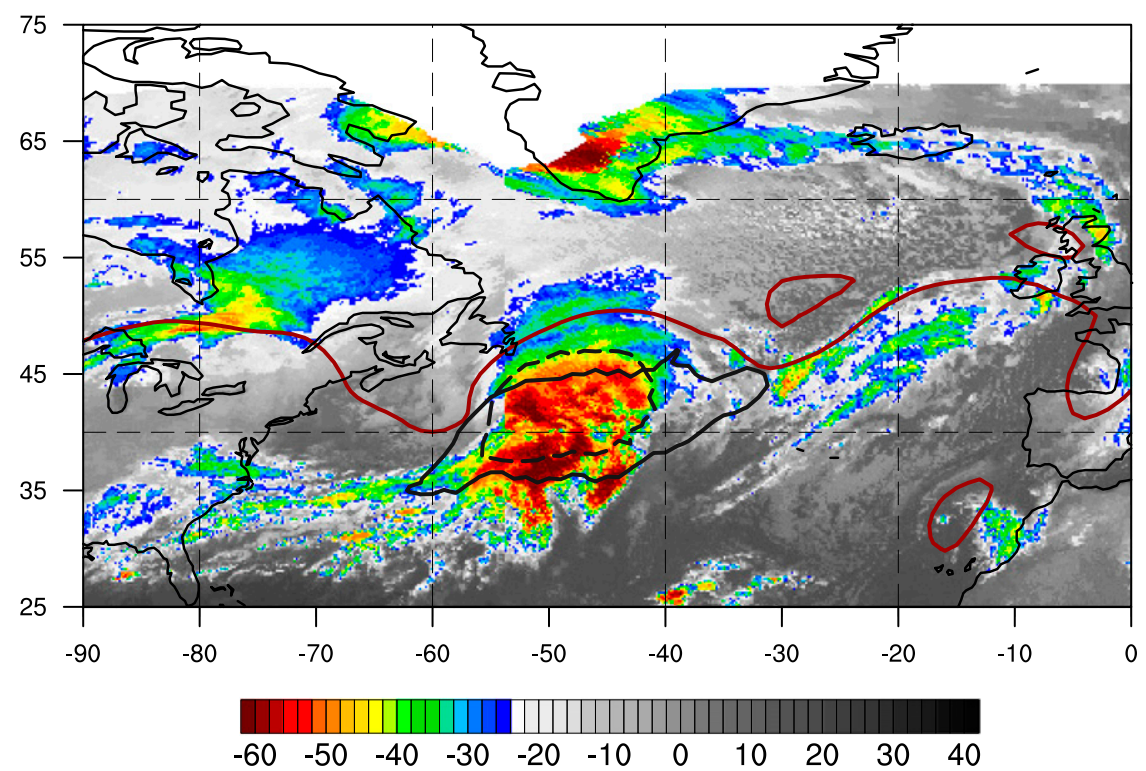

FIG. 6. False-color infrared satellite image (brightness temperature; ${ }^{\circ} \mathrm{C}$ ) at $0600 \mathrm{UTC} 7 \mathrm{Jan}$ 1990 derived from the GridSat-B1 data. Overlaid is the 2-PVU contour on $315 \mathrm{~K}$ (red) derived from ERA-Interim and the smoothed contours marking the grid points with at least one WCB trajectory with $p>500 \mathrm{hPa}$ (black solid) and $p<500 \mathrm{hPa}$ (black dashed).

strongest intensity in terms of SLP $(936 \mathrm{hPa})$ is only reached $12 \mathrm{~h}$ later (Fig. $3 \mathrm{~g}$ ). At that time the cyclone is located below a deep tropopause (Fig. 5d) and associated with a T-bone frontal structure and an intense bent-back front (Fig. 3h; Shapiro and Keyser 1990). Weaker WCB-related PV production now only occurs along the warm front (Fig. $3 \mathrm{~g}$ ), and the PV tower is starting to decay (Fig. 5d).

In summary, this $\mathrm{C} 1$ case study suggests that the WCB played a significant role for cyclone development. The WCB-induced diabatic PV production in the cyclone center led to the formation of a strong low-level PV anomaly, which significantly enhanced the low-level circulation and thereby contributed to the explosive intensification of the cyclone.

\section{b. Spatial structure of the C1 cyclones}

\section{1) Structure At $t=0 \mathrm{~h}$}

Figure $7 \mathrm{a}$ shows the horizontal structure of the composite cyclone at $t=0 \mathrm{~h}$ in terms of SLP, PV on the $315-\mathrm{K}$ isentrope, and the WCB trajectory frequency. The coordinates are defined relative to the position of the SLP minimum, which is relocated to $0^{\circ}$ longitude and latitude, and the fields are averaged at these coordinates. Low-level and upper-level WCB trajectory frequencies are shown. The values are calculated such that they denote the percentage of $\mathrm{C} 1$ cyclones with at least one WCB air parcel with $p>500 \mathrm{hPa}$ and $p<500 \mathrm{hPa}$, respectively, at that grid point. For instance, a low-level trajectory frequency of $50 \%$ indicates that at that grid point 250 out of the $500 \mathrm{C} 1$ cyclones are associated with at least one WCB trajectory somewhere between 1000 and $500 \mathrm{hPa}$. Additionally, the occurrence frequency of WCB trajectories with a high PV value of more than $1 \mathrm{PVU}$ within the layer $900<p<700 \mathrm{hPa}$ is shown [similar to the high low-level PV (HLPV) WCB trajectories introduced by Madonna et al. (2014)] to get an impression of where the strongest WCB-related diabatic PV production occurs.

At $t=0 \mathrm{~h}$ the composite cyclone is located to the east of an upper-level trough (Fig. 7a) within a region of strong baroclinicity (not shown). Already at that early time step, a strong WCB is present in the cyclone's warm sector. The highest frequency of WCB trajectories at low levels is located slightly to the east of the cyclone center, with values of more than $70 \%$, while the highest frequency of HLPV trajectories occurs directly in the cyclone center. ${ }^{2}$ The WCB outflow into the downstream ridge is still relatively weak and has its

\footnotetext{
${ }^{2}$ Note that the centering of the composites on the SLP minimum favors the occurrence of high WCB trajectory frequencies near the center of the composite cyclone, while it more strongly smears out the signal farther away from the cyclone-for example, along the fronts. The high frequency of WCB trajectories at low levels in the cyclone center is nevertheless remarkable and consistent with the case study discussed earlier.
} 

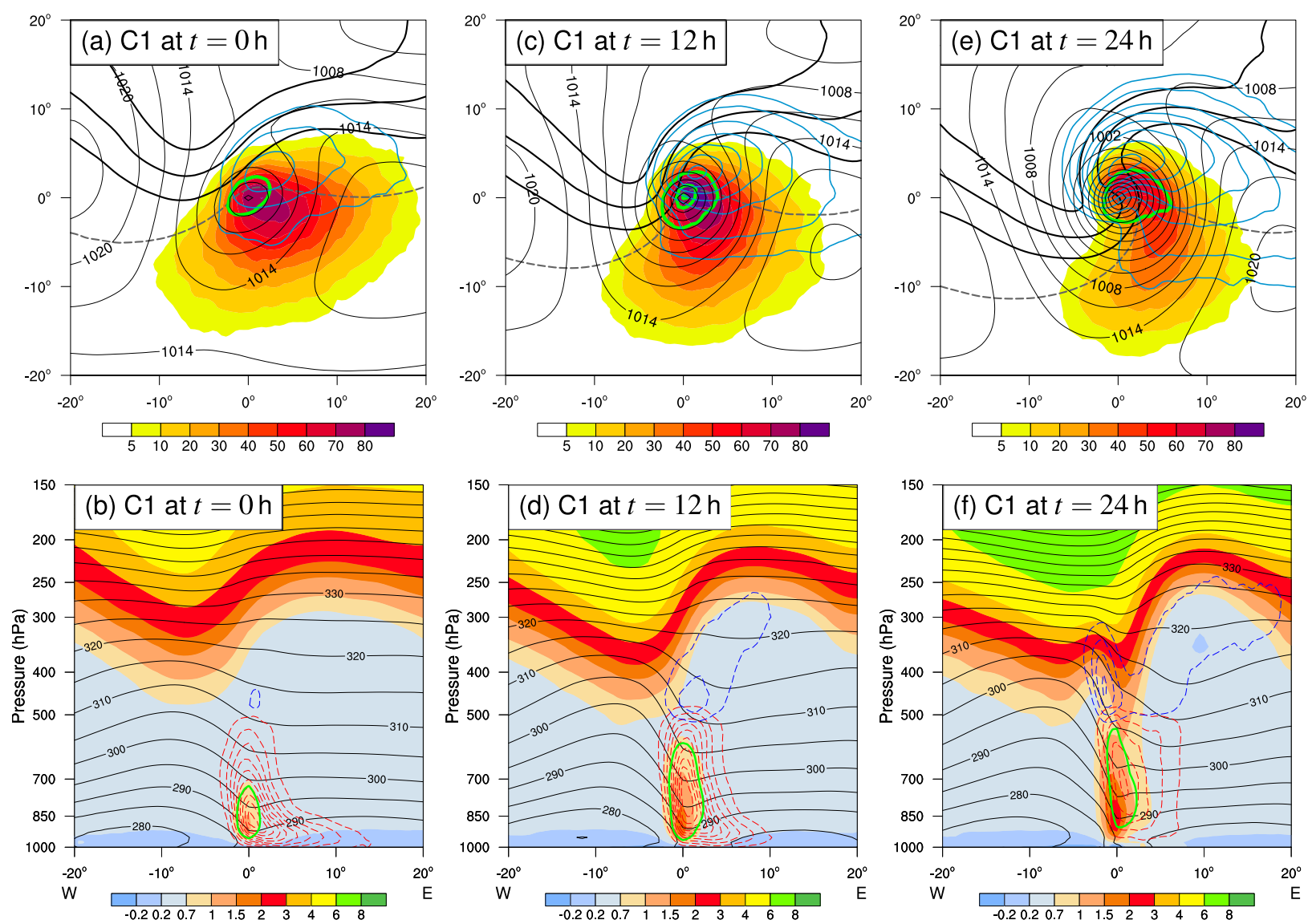

FIG. 7. Composites of $\mathrm{C} 1$ cyclones (a),(b) at the beginning $(t=0 \mathrm{~h}) ;(\mathrm{c}),(\mathrm{d})$ in the middle $(t=12 \mathrm{~h})$; and (e),(f) at the end ( $t=24 \mathrm{~h})$ of their strongest SLP deepening. (top) Frequency of low-level WCB trajectories with $p>500 \mathrm{hPa}$ (\%; shading; see text for details), of upper-level WCB trajectories with $p<500 \mathrm{hPa}$ (blue contours at $5 \%, 10 \%, 20 \%, \ldots, 80 \%$ ), and of WCB trajectories with $900<p<$ $700 \mathrm{hPa}$ and PV $>1 \mathrm{PVU}$ (green contours for 10\%, 50\%, and 65\%), SLP (thin black contours every $3 \mathrm{hPa}$ ), PV on $315 \mathrm{~K}$ (thick black contours for 2, 3, and $4 \mathrm{PVU}$ ), and potential temperature on $850 \mathrm{hPa}$ (black dashed contour for $\theta=290 \mathrm{~K}$ ). (bottom) West-east vertical cross sections through the center of the composite cyclone (from $-20^{\circ}$ to $20^{\circ}$ ) showing PV (PVU; shading), potential temperature (contours every $5 \mathrm{~K}$ ), and relative WCB trajectory density (\%; red dashed for WCB trajectories with $p>500 \mathrm{hPa}$, blue dashed for WCB trajectories with $p<500 \mathrm{hPa}$, contours every $5 \%$, and green solid for the $10 \%$ frequency of trajectories with $p>500 \mathrm{hPa}$ and $\mathrm{PV}>1 \mathrm{PVU}$ ).

maximum $(\sim 20 \%)$ slightly north of the low-level maximum.

The west-east vertical section across the center of the composite cyclone confirms the presence of a broad trough to the west and a ridge to the east of the cyclone (Fig. 7b). Furthermore, it shows a large relative WCB trajectory density ${ }^{3}$ between 1000 and $700 \mathrm{hPa}$ near the cyclone center, with maximum values of about $50 \%$. It is collocated with a positive PV anomaly, pointing to significant WCB-related diabatic PV production. Ahead of

\footnotetext{
${ }^{3}$ The relative WCB trajectory density is defined as the WCB trajectory density normalized by the density of the WCB starting points, which is the maximum possible WCB trajectory density. For example, a WCB trajectory density of $50 \%$ in a certain air volume indicates that $50 \%$ of the air in that volume is WCB air.
}

the cyclone center, most trajectories are still in the boundary layer.

\section{2) Structure AT $t=12 \mathrm{H}$}

The SLP of the composite cyclone has dropped by more than $13 \mathrm{hPa}$ to about $988 \mathrm{hPa} 12 \mathrm{~h}$ later (Fig. $7 \mathrm{c}$ ). The 850-hPa potential temperature field in Fig. 8a reveals the formation of surface cold and warm fronts, although they appear rather weak as a result of the compositing. The WCB has strengthened, and the area around the cyclone center associated with the most intense WCB-related PV production has increased (Fig. 7c). In the same region, high low-level PV (Fig. 8a) and a pronounced precipitation signal (Fig. $8 \mathrm{~b}$ ) point to strong latent heating by condensational processes. The diabatically produced PV anomaly extends from the surface up to about $550 \mathrm{hPa}$ within an area of strong 

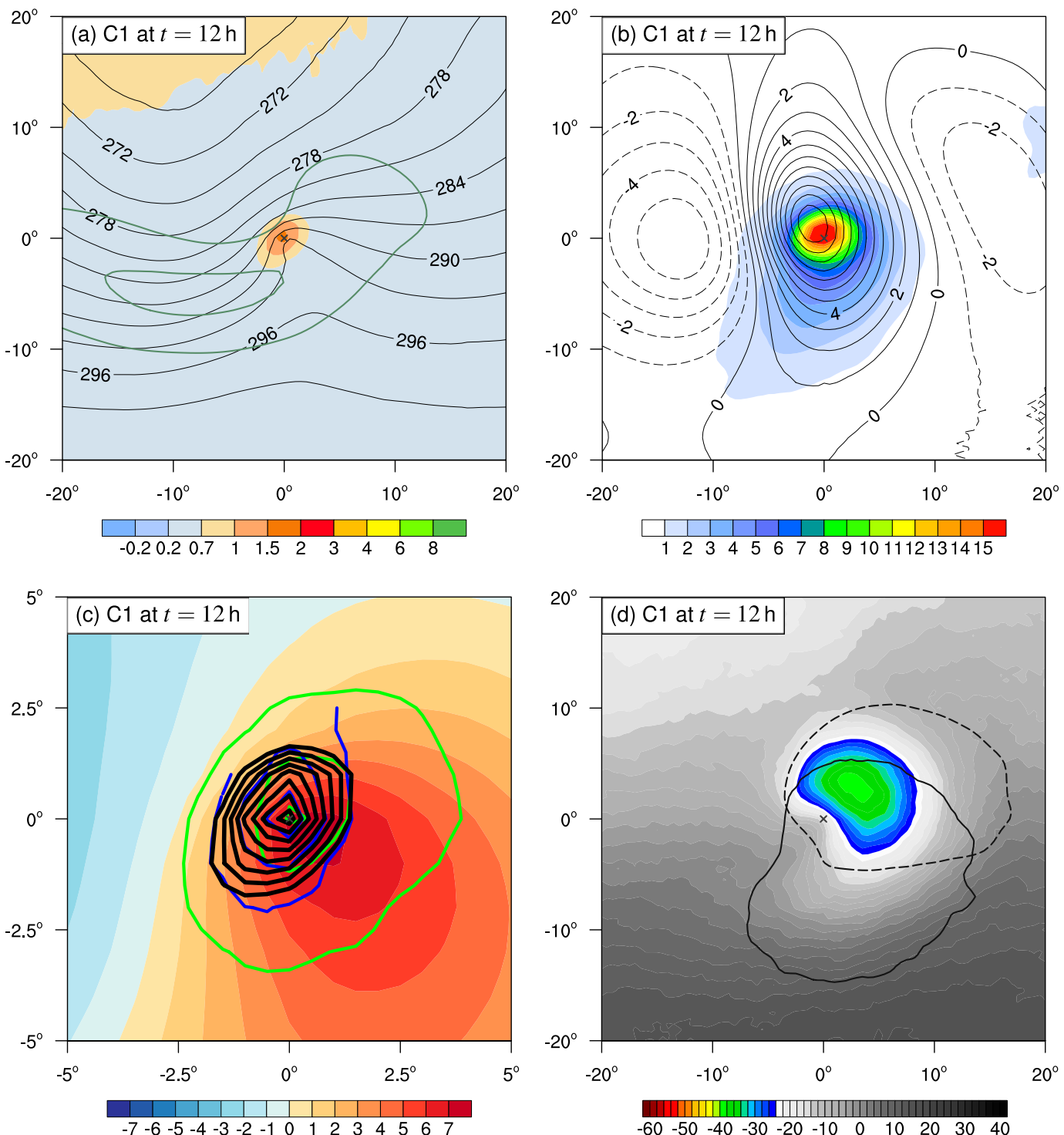

FIG. 8. C1 composites at $t=12 \mathrm{~h}$ of (a) PV (PVU; shading) and potential temperature (black contours every $3 \mathrm{~K}$ ) at $850 \mathrm{hPa}$ and wind speed at $250 \mathrm{hPa}$ (green contours for 50 and $60 \mathrm{~m} \mathrm{~s}^{-1}$ ); (b) 6-h accumulated precipitation (mm; shading) and upper-level induced QG vertical motion at $700 \mathrm{hPa}$ (black contours every $10^{-3} \mathrm{~m} \mathrm{~s}^{-1}$, dashed for negative values); (c) potential temperature anomaly at $900 \mathrm{hPa}$ (K; shading) and PV anomaly at $850 \mathrm{hPa}$ (black contours from 0.5 PVU every 0.1 PVU), both obtained by subtracting the December-February climatological mean from the field at each location, frequency of WCB trajectories with $900<p<700 \mathrm{hPa}$ and PV $>1 \mathrm{PVU}$ (green contours for $10 \%, 50 \%$, and $65 \%$ ) and their mean PV value (blue contours for 1.3, 1.4, and $1.5 \mathrm{PVU}$; only shown for areas where the green contour is $>10 \%$ ); and (d) brightness temperature of the false-color infrared satellite imagery $\left({ }^{\circ} \mathrm{C}\right.$; shading) derived from the GridSat-B1 data, overlaid by the $10 \%$ contours of low-level (black solid) and upper-level (black dashed) WCB trajectory frequencies. The gray cross marks the position of the cyclone center. Please note that $(\mathrm{c})$ is enlarged to the $10^{\circ} \times 10^{\circ}$ box around the cyclone center.

WCB ascent (Fig. 7d), illustrating the key role of the WCB for the formation of the intense vortex. The zoom on the region around the cyclone center in Fig. $8 \mathrm{c}$ emphasizes the coincidence of the low-level PV anomaly (maximum of more than 1.2 PVU; see black contours) and the WCB-related PV production (maximum HLPV
WCB trajectory frequency of $65 \%$, with a mean PV value of 1.5 PVU; see green and blue contours) with the cyclone center. Figure 8c also reveals that the nearsurface potential temperature anomaly is positive in the cyclone center, but the strongest anomaly (more than $7 \mathrm{~K}$ ) is located to the southeast of the cyclone center. This 
indicates that, applying a conceptual piecewise PV inversion, both the lower-boundary warm anomaly and the low-level PV anomaly contribute to the near-surface cyclonic circulation, but the circulation induced by the low-level PV anomaly is stronger, as it is perfectly aligned with the overall cyclonic circulation. As shown in the supplemental material, this conclusion is supported by the fact that during cyclone intensification, low-level PV increases more strongly than the low-level potential temperature anomaly.

The low-level vortex is located at the leading edge of a pronounced cyclonically breaking upper-level wave (Figs. 7c,d) below the left exit region of an intense jet (Fig. 8a). Consistently, the upper-level induced QG vertical motion at $700 \mathrm{hPa}$ reveals a very strong upperlevel forcing for ascent in the region of the developing cyclone and the ascending WCB (Fig. 8b). The intense QG forcing is essential for the ascent of the WCB trajectories, while the low-PV air in the WCB outflow (see blue lines in Figs. 7c,d) most likely enhances the upperlevel forcing by amplifying the downstream ridge. The existence and interplay of a strong upper-level forcing and an intense, diabatically produced low-level PV anomaly explains the explosive intensification of the $\mathrm{C} 1$ cyclones.

The occurrence of strong WCB-related cloud formation in the $\mathrm{C} 1$ cyclones is confirmed by satellite imagery. Figure $8 \mathrm{~d}$ shows an infrared satellite composite of the $\mathrm{C} 1$ cyclones at $t=12 \mathrm{~h}$. The satellite data are retrieved from the GridSat-B1 data (Knapp et al. 2011), which is available from January 1980 onward. From the $500 \mathrm{C} 1$ cyclones all except the 13 cases occurring in 1979 are included in the composite. The composite reveals the presence of a cyclonically curved cloud band with a gradual decrease of brightness temperature, from warm, low-to-midlevel clouds south and southeast of the cyclone center, to cold, high-reaching clouds east and northeast. The cloud band has the characteristic comma shape often found in developing cyclones, with the comma head located above the storm center and at the warm front and the tail along the cold front. It exhibits a strong agreement with the comma-shaped precipitation signal (Fig. 8b) and the spatial distribution of the ascending WCB and, thus, provides observational evidence for the existence of a WCB cloud band associated with significant diabatic processes.

\section{3) Structure AT $t=24 \mathrm{~h}$ AND SUbSEQUENT DEVELOPMENT}

During the following $12 \mathrm{~h}$, the composite cyclone further intensifies to a minimum SLP of about $972 \mathrm{hPa}$, accompanied by continuous low-level diabatic PV production, and the LC2-type rolling up of the upper-level wave (Figs. 7e,f). A low-level vortex with PV values of more than 1.5 PVU extends up to about $550 \mathrm{hPa}$, with maximum values of more than $2 \mathrm{PVU}$ near $850 \mathrm{hPa}$ (Fig. 7f). The vortex is connected to a narrow filament of stratospheric air penetrating deep into the troposphere, and together they form an intense PV tower. It is at this time that the composite cyclone reaches its strongest intensity in terms of low-level relative vorticity (see supplemental material).

While the WCB trajectory frequency at low levels has slightly decreased compared to previous time steps, the WCB outflow has strengthened (Figs. 7e,f). The structure of the composite WCB outflow suggests that the WCB is associated with a cyclonic and an anticyclonic branch, as noted earlier for the case study (cf. Fig. 3e). In the west-east vertical section the cyclonically turning branch of the WCB outflow is visible between about 300 and $500 \mathrm{hPa}$ slightly to the west of the low-level vortex, in a region where the upper-level trough is less pronounced and maybe eroded by diabatic processes (Fig. 7f). The anticyclonic branch east and northeast of the cyclone center reaches higher levels, consistent with the findings of Martínez-Alvarado et al. (2014), and contributes significantly to the amplification of the downstream ridge. As verified by choosing a larger compositing region (not shown), the ridge amplification in turn promotes Rossby wave breaking and the formation of a pronounced trough about $2500 \mathrm{~km}$ downstream of the composite cyclone. This suggests that the WCB associated with the $\mathrm{C} 1$ cyclones also plays a fundamental role for the wave dynamics at the tropopause level by strongly influencing the downstream flow evolution.

The strongest intensity in terms of SLP is reached $12 \mathrm{~h}$ later. By then the WCB-related PV production has strongly decreased, and the composite storm has become located below a deep tropopause (not shown).

Note that the structure and evolution of the composite cyclone exhibits strong similarities to the case study discussed above: pronounced WCB-related diabatic PV production in the cyclone center in a region of strong baroclinicity, a cyclonically breaking upper-level wave, and the formation of a PV tower toward the end of the intensification. An examination of the individual cases revealed that the composite well represents the main characteristics of $\mathrm{C} 1$ cyclones. For instance, two prominent $\mathrm{C} 1$ cyclones that have been investigated in detail, the Presidents' Day snowstorm and the windstorm Xynthia, both bear strong resemblance to the mean C1 composite (not shown). However, of course there is some case-to-case variability, with the importance of individual dynamical and physical processes varying among the cyclones. The most striking common feature 
among the majority of the $\mathrm{C} 1$ cyclones is the concentration of high WCB-related PV production in the cyclone center during the explosive intensification. This implies that $\mathrm{C} 1$ cyclones are primarily associated with WCBs of type W2, which ascend close to the cyclone center.

\section{Category C2-Weakly intensifying cyclones with strong WCBs}

\section{a. Spatial structure of the C2a cyclones}

The composites of the $29 \mathrm{C} 2 \mathrm{a}$ cyclones at $t=12 \mathrm{~h}$ are shown in Fig. 9. The composite cyclone is associated with a weak small-scale SLP signal (Fig. 9a). It is located south of a strong baroclinic zone in a region of warm air (Fig. 9c) and a pronounced positive surface $\theta$ anomaly (Fig. 9e; note also the absence of a cold anomaly). An intense WCB is present (Figs. 9a,e), with a maximum WCB trajectory frequency at low levels of $80 \%$ slightly east of the cyclone center, a maximum HLPV trajectory frequency of $50 \%$ directly in the cyclone center, and a WCB outflow maximum of $60 \%$ to the northeast (similar to $\mathrm{C} 1$; cf. Figs. $7 \mathrm{c}$ and $8 \mathrm{c}$ ). The area of strong PV production by HLPV WCB trajectories in and around the cyclone center (Figs. 9a, e) coincides with an intense low-level vortex with high PV values of more than 1 PVU (Figs. 9b,c) and intense precipitation (Fig. 9d). The low-level vortex extends up to about $700 \mathrm{hPa}$ within a region of strong WCB ascent (Fig. 9b). It is not as strong as in C1 (cf. Fig. 7d) but still constitutes a pronounced positive $\mathrm{PV}$ anomaly (Fig. 9e). Farther to the east, the majority of the WCB trajectories is still located in the boundary layer and will ascend along the baroclinic zone during the subsequent hours (Fig. 9b).

In contrast to $\mathrm{C} 1$, the composite cyclone is located far south of a weak upper-level wave on $315 \mathrm{~K}$ (Fig. 9a), and above the shallow low-level vortex the tropopause is high and relatively undisturbed (Fig. 9b). Consistently, the upper-level forcing for ascent is very weak near the cyclone center (Fig. 9d), with about 3-times-lower values than in $\mathrm{C} 1$.

In the satellite composite of the $29 \mathrm{C} 2 \mathrm{a}$ cyclones, strong cloud formation is evident in the region of the ascending WCB (Fig. 9f), corroborating the importance of WCB-related cloud diabatic processes for these cyclones. As for $\mathrm{C} 1$, the brightness temperature gradually decreases from the cyclone's warm sector toward the area of strong WCB ascent east and northeast of the cyclone center. However, in $\mathrm{C} 1$ the cloud band is more cyclonically curved, and the clouds reach higher levels (cf. Fig. 8d). The lower cloud-top height in $\mathrm{C} 2 \mathrm{a}$ is in agreement with the lower height of the WCB outflow seen in Fig. 9b and likely a consequence of the weak upper-level forcing for ascent.

Over the subsequent hours the situation does not change substantially, and the composite cyclone intensifies only weakly (see supplemental Figs. S1, S2, and S4). Continuous WCB-related diabatic PV production further strengthens the low-level vortex, but the smallscale cyclone remains in a region of weak upper-level forcing for ascent below a relatively undisturbed tropopause (in contrast to $\mathrm{C} 1$, where an intense $\mathrm{PV}$ tower develops). The absence of a significant upper-level forcing during the entire development of $\mathrm{C} 2 \mathrm{a}$ cyclones is the main difference from $\mathrm{C} 1$ and explains why they are not intensifying despite the strong WCB-related PV production.

The characteristics of the $\mathrm{C} 2 \mathrm{a}$ cyclones bear strong resemblance to DRWs: a pronounced low-level positive PV anomaly in the center of a small-scale cyclone, its rapid eastward propagation along an intense baroclinic zone through continuous PV generation by ascending air to the east of the present low-level vortex, and the absence of a significant upper-level forcing. Indeed, among the $\mathrm{C} 2$ a cyclones are four cases that have also been found in the group of nondeepening DRWs in the 10-yr climatology of Boettcher and Wernli (2013). ${ }^{4}$ The C2a cyclones therefore represent a subclass of nondeepening DRWs where the low-level vortex is generated by a strong WCB.

\section{b. Spatial structure of the C2b cyclones}

Figure 10 shows the composites of the 72 cyclones in the second subcategory of $\mathrm{C} 2$ at $t=12 \mathrm{~h}$. A pronounced, meridionally elongated upper-level wave is located upstream of the composite cyclone (Fig. 10a), which, however, is characterized by a weak PV gradient in comparison to $\mathrm{C} 1$ (cf. Fig. 7a). Also the baroclinicity, the surface warm anomaly, and the upper-level flow in the region of the developing cyclone, as well as the upperlevel induced QG vertical motion at $700 \mathrm{hPa}$, are weaker than in $\mathrm{C} 1$ (Figs. 10c-e).

Overall the $\mathrm{C} 2 \mathrm{~b}$ cyclones have almost the same WCB trajectory mass as $\mathrm{C} 1$, and a larger mass than $\mathrm{C} 2 \mathrm{a}$ (see supplemental Fig. S1), but in $\mathrm{C} 2 \mathrm{~b}$ they are distributed over a larger area. In the cyclone center the WCB trajectory frequency is lower than in both $\mathrm{C} 1$ and $\mathrm{C} 2 \mathrm{a}$ (but still has a maximum), and also the HLPV trajectory frequency is lower, whereas more trajectories are

\footnotetext{
${ }^{4}$ However, the comparison is not straightforward, as Boettcher and Wernli (2013) used ECMWF operational analyses with a different model setup and higher resolution than ERA-Interim.
} 

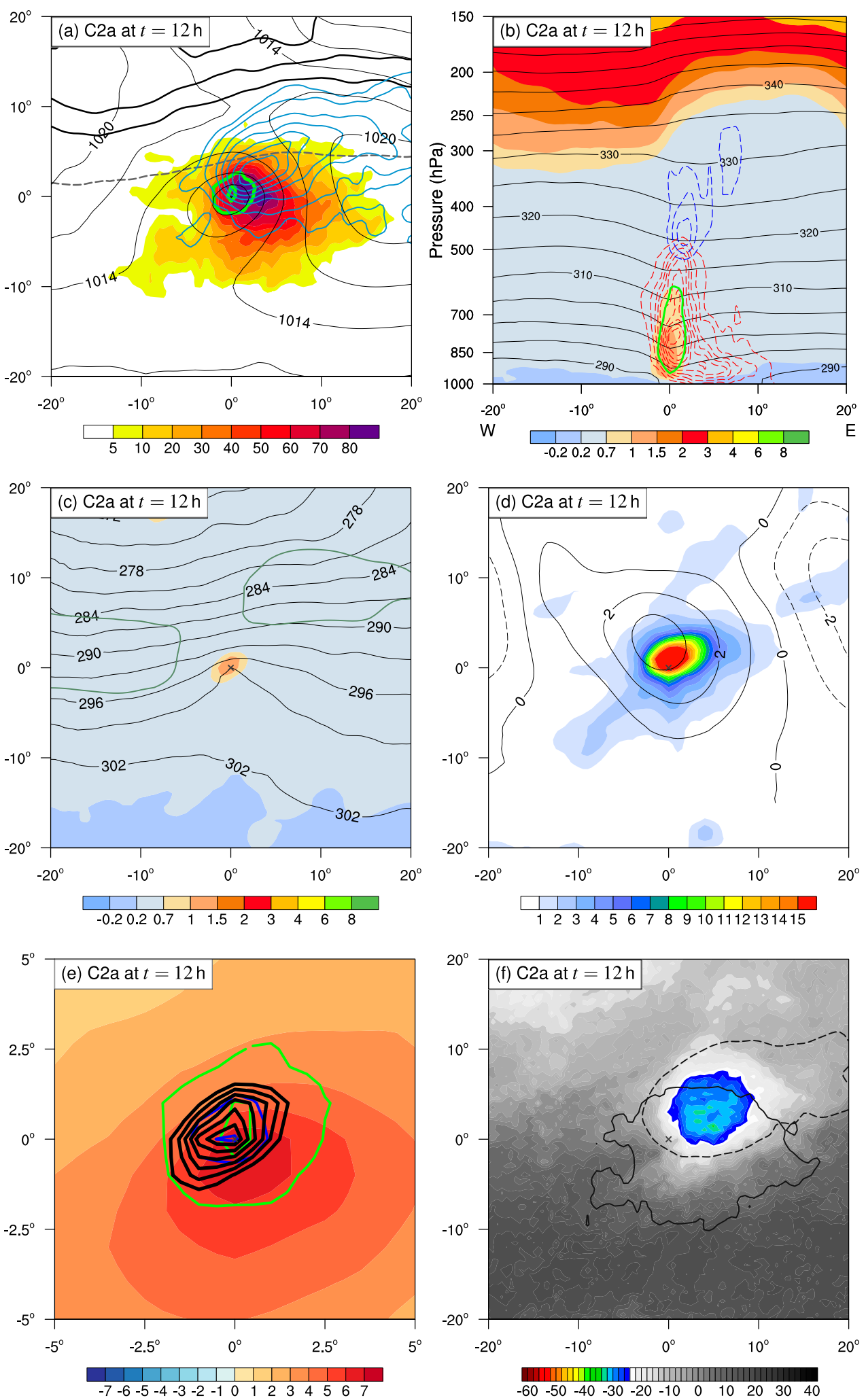

FIG. 9. C2a composites at $t=12$ h. Fields as in (a) Fig. 7c, (b) Fig. 7d, and (c)-(f) Fig. 8. 

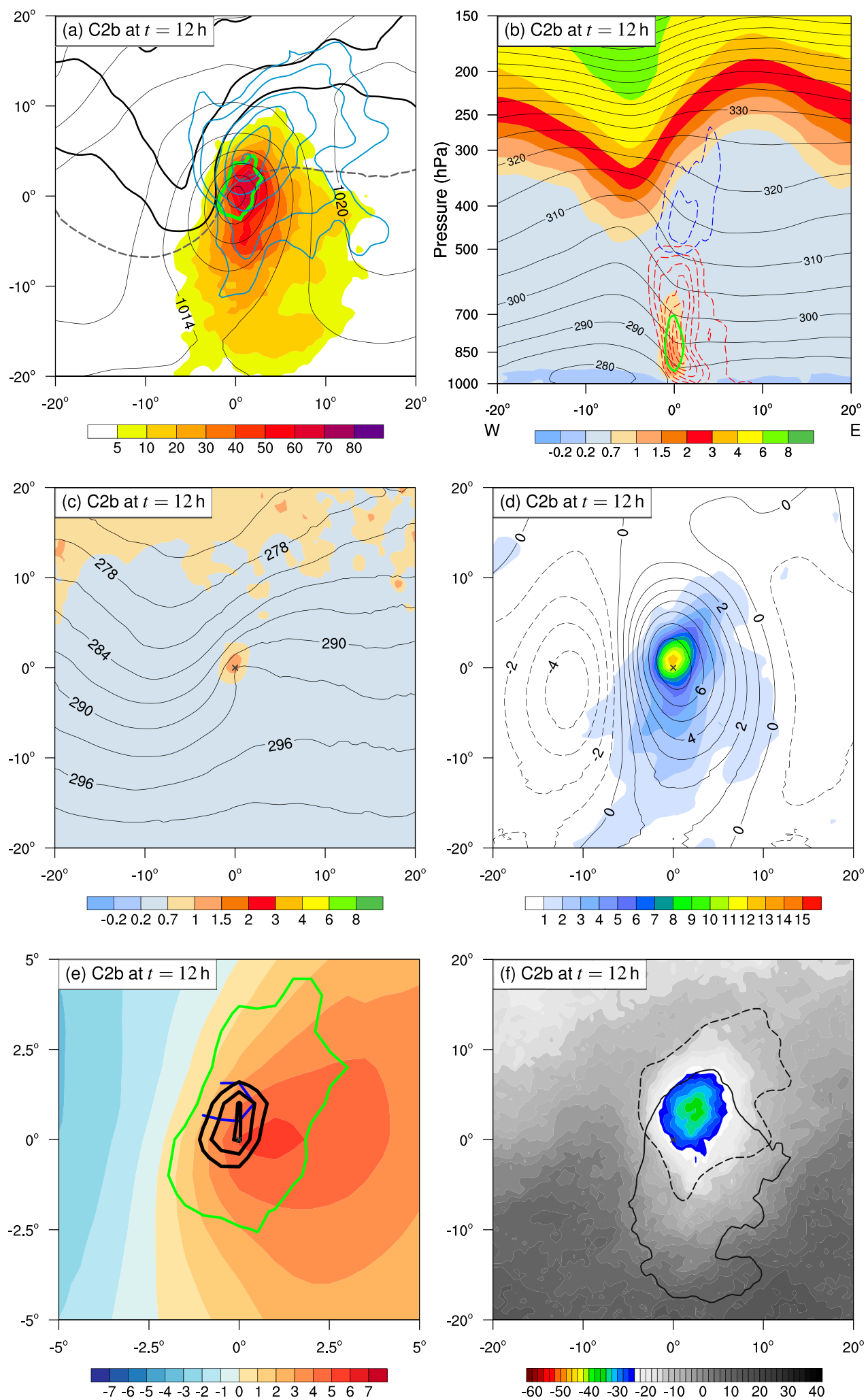

FIG. 10. As in Fig. 9, but for C2b. 
located relatively far away, particularly far south of the cyclone center (Fig. 10a). The WCB outflow is shifted north and slightly eastward with respect to the lowlevel trajectory positions.

In the cross section, a relatively broad upper-level trough is evident west of a low-level vortex with PV values of more than $1 \mathrm{PVU}$ in the cyclone center (Fig. 10b). The latter indicates that also the $\mathrm{C} 2 \mathrm{~b}$ cyclones are associated with intense diabatic $\mathrm{PV}$ production. However, the vortex is weaker than in $\mathrm{C} 1$, with a positive $\mathrm{PV}$ anomaly of only $0.7 \mathrm{PVU}$ at $850 \mathrm{hPa}$ (Fig. 10e) compared to 1.2 PVU in $\mathrm{C} 1$, and also the vertical extent of the vortex is smaller (cf. Figs. $7 \mathrm{~d}$ and $8 \mathrm{c}$ ). This is consistent with the lower relative WCB trajectory density near the cyclone center and the smaller number of HLPV WCB trajectories (Figs. 10a,b,e). Interestingly, nonetheless the density of the upper-level trajectories above the lowlevel vortex is of about the same magnitude as in $\mathrm{C} 1$. The low-PV air in the WCB outflow directly above the cyclone center potentially impedes the stratospheric air to descend and connect with the low-level vortex.

Comparison of the spatial distribution of the WCB trajectories at low levels with the precipitation signal in Fig. 10d shows a strong correspondence between the two quantities: the maximum precipitation also occurs near the cyclone center, but it is weaker than in $\mathrm{C} 1$ and $\mathrm{C} 2 \mathrm{a}$, while an elongated band of precipitation connects the cyclone center with the border of the compositing region far to the southwest. It indicates cold-frontal precipitation, and the correspondence with the WCB trajectories implies that strong WCB ascent-and associated precipitation-occurs along the cold front in type W1 flows.

Note that the composites are not rotated with respect to the orientation of the cold front, and because of the variability in the cold frontal position among the individual cyclones its features are smeared out by the compositing. Therefore, the cold front appears relatively weak in the signal of $\theta$ (Fig. 10c), precipitation (Fig. 10d), and WCB trajectory frequency (Fig. 10a), but it is remarkable that nevertheless such a clear signal is evident, in contrast to $\mathrm{C} 1$ and particularly $\mathrm{C} 2 \mathrm{a}$. An examination of the individual $\mathrm{C} 2 \mathrm{~b}$ cyclones revealed that in most cases the WCB ascent and associated PV production concentrated along a pronounced cold front far from the cyclone center (not shown). The cold front was typically associated with a narrow stratospheric PV streamer or a cutoff. The orientation of the PV streamer varied between LC1 type, neutral, and LC2 type, and this variability can explain the relatively broad upperlevel disturbance in the composite (Fig. 10a).

In the satellite composite (Fig. 10f; containing the 69 cyclones occurring from 1980 onward) the cold frontal cloud band is indicated by increasing brightness temperatures from the southern edge of the compositing region toward the cyclone center. It nicely correlates with the spatial distribution of the ascending WCB trajectories. The highest-reaching clouds are located in the region of strongest WCB ascent slightly northeast of the cyclone center. Their cloud top is lower than in $\mathrm{C} 1$, consistent with the weaker upper-level forcing for ascent.

During the following hours, the described fields remain very similar, and the composite cyclone does not intensify considerably (see supplemental Figs. S1, S2, and S5). The westward tilt between the cyclone center and the upperlevel trough remains almost constant, and no PV tower develops, contrary to $\mathrm{C} 1$.

In summary, the absence of intensification in the $\mathrm{C} 2 \mathrm{~b}$ category despite the strong WCB can be explained by several factors: (i) In contrast to $\mathrm{C} 1$, much of the WCB ascent and associated PV production occurs in many cases at the cold front far south of the cyclone center, in WCBs of type W1. The fraction ascending near the cyclone center is much lower and associated with a weaker diabatically produced vortex. This indicates that the location of the WCB-related PV production relative to the cyclone center plays an important role for its impact on cyclone development. (ii) The upperlevel disturbance has a weaker PV gradient than in C1, and accordingly the upper-level forcing for ascent is weaker. (iii) Directly above the low-level vortex, the density of the upper-level WCB trajectories is higher than in $\mathrm{C} 1$, particularly toward the end of intensification, which potentially additionally impedes the formation of a PV tower.

\section{Category C3-Explosively intensifying cyclones with weak WCBs}

The mean spatial structure of the $154 \mathrm{C} 3$ cyclones at $t=12 \mathrm{~h}$ is shown in Fig. 11. The SLP field reveals a smallscale low pressure system in the center of the composite and another system to the northeast (Fig. 11a). In agreement with the high latitude of most $\mathrm{C} 3$ cyclones (Fig. 2), the tropopause is low (Fig. 11a) and it is considerably colder than in the other categories (Fig. 11c). The positive surface $\theta$ anomaly in the warm sector is relatively weak, while the cold sector is associated with a pronounced negative anomaly (Fig. 11e). The composite cyclone is located at the left jet exit in a region of relatively strong low-level baroclinicity (Fig. 11c). Both fields are pronounced, but weaker than in $\mathrm{C} 1$ (cf. Fig. 8a). Upstream of the cyclone center, a small disturbance is present on the $315-\mathrm{K}$ isentrope that is associated with a strong PV gradient (Fig. 11a). In the 

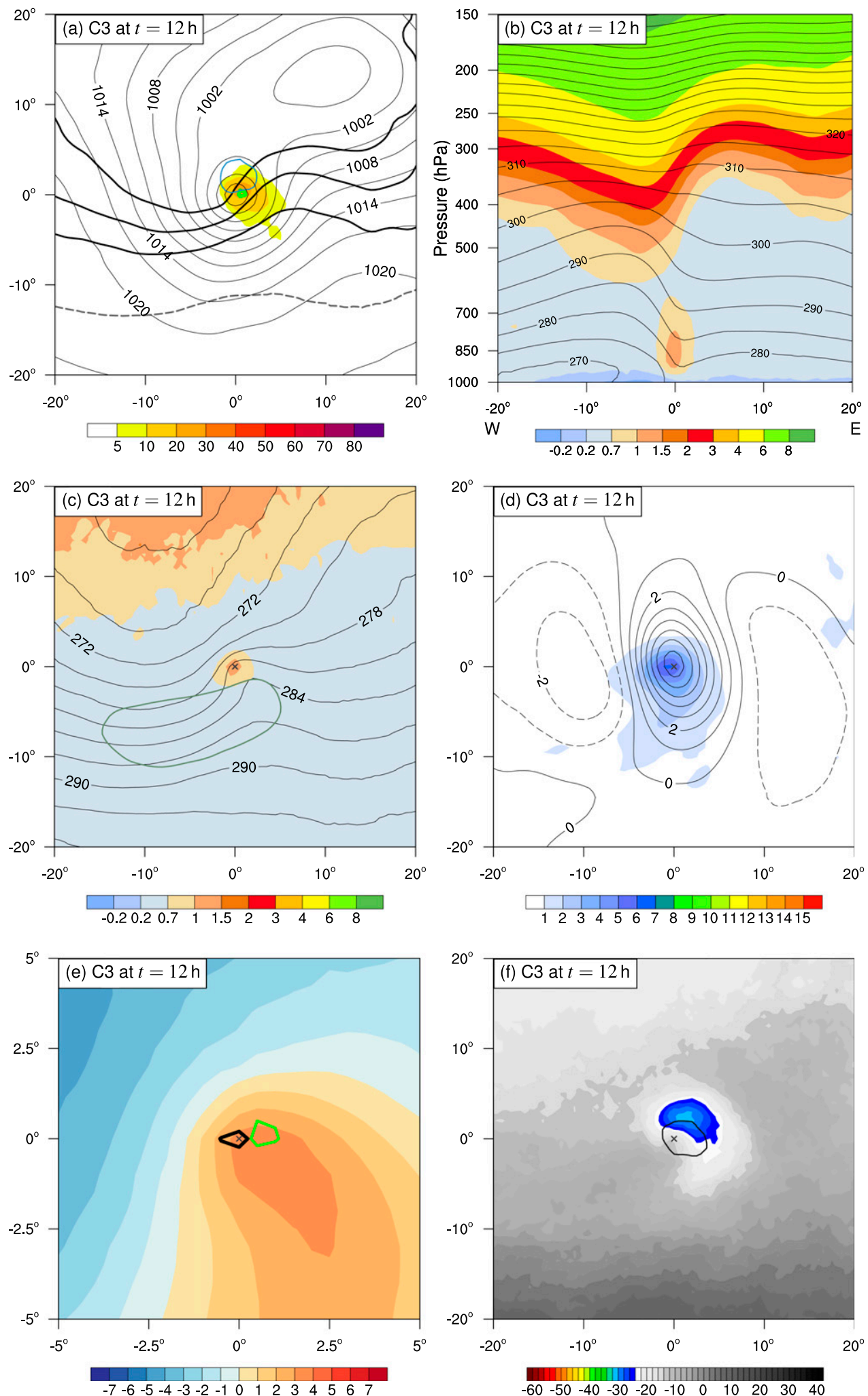

FIG. 11. As in Fig. 9, but for C3. 
cross section a deep trough is evident east of the cyclone (Fig. 11b). The upper-level forced QG ascent at $700 \mathrm{hPa}$ is weaker than in $\mathrm{C} 1$ and of about the same magnitude as in C2b (Fig. 11d).

As expected, the WCB is weak, with a maximum WCB trajectory frequency of $20 \%$ at low levels near the cyclone center, a $10 \%$ frequency of HLPV WCB trajectories in the same region, and a $5 \%$ frequency in the WCB outflow slightly to the north (Figs. 11a,e). The precipitation signal is much weaker than in the other categories (Fig. 11d), and also the commashaped cloud in the satellite composite is at lower height (Fig. 11f; containing $151 \mathrm{C} 3$ cyclones). Nevertheless, above the cyclone center a low-level vortex of a similar strength as in $\mathrm{C} 2 \mathrm{a}$ and $\mathrm{C} 2 \mathrm{~b}$ indicates that also in $\mathrm{C} 3$ diabatic processes play a role (Figs. 11b,c). The small number of WCB trajectories suggests that the low-level PV production is to a large extent related to diabatic processes that are independent of WCBs. Note, however, that the PV anomaly of the low-level vortex amounts to only 0.5 PVU (Fig. 11e), which is less than in the other categories, particularly $\mathrm{C} 1$ and $\mathrm{C} 2 \mathrm{a}$.

Over the next hours, the composite cyclone strongly intensifies and grows in size at the expense of the cyclone to the northeast (see supplemental Fig. S6). The pattern suggests a merging of the two systems, which would explain the rapid SLP decrease. This indeed occurs in some $\mathrm{C} 3$ cyclones, but often they remain isolated and simply develop in the vicinity of another, decaying system, which appears as a merging signal in the composite. Toward the end of the intensification, a weak PV tower develops through a further lowering of the tropopause and ongoing diabatic processes.

For the $\mathrm{C} 3$ cyclones at high latitudes $\left(>60^{\circ} \mathrm{N}\right.$ in Fig. 2), it is noted that they can be located in regions where the troposphere is lower than the pressure threshold of $600 \mathrm{hPa}$ used to identify WCBs. This raises the question whether these cyclones are nevertheless connected to strong diabatic processes in airstreams ascending less than $600 \mathrm{hPa}$. However, case studies showed that the high-latitude $\mathrm{C} 3$ cyclones are associated with very low values of low-level specific humidity, weak precipitation, and accordingly weak diabatic processes. This confirms that the weak WCB strength in these cyclones is not simply due to the $600-\mathrm{hPa}$ WCB ascent criterion used in this study.

To summarize, C3 cyclones are associated with a relatively pronounced baroclinicity, jet and upper-level forcing, and some low-level diabatic PV production. However, all these fields are weaker than in $\mathrm{C} 1$, which can in part be attributed to the smaller mean Bergeron value of $\mathrm{C} 3$, as discussed in section 3. Furthermore, an examination of the individual $\mathrm{C} 3$ cyclones revealed that the category is rather inhomogeneous, with various types of explosive intensification.

\section{Summary and conclusions}

The present study comprises a first systematic analysis of the statistical relationship between cyclone intensification and WCB strength. The analysis is based on WCB and cyclone climatologies compiled from the ERA-Interim dataset for the NH winter during 19792014. For the $\sim 5000$ cyclones in the dataset, it has been investigated whether there is a connection between cyclone intensification and the strength of the associated WCB. Cyclone intensification has been quantified as the latitude-adjusted maximum central SLP deepening over $24 \mathrm{~h}$ along a track, as introduced by Sanders and Gyakum (1980). The WCB strength has been measured by the number and mass of the WCB trajectories associated with the cyclone at low levels (pressure $>500 \mathrm{hPa}$ ) during the $24 \mathrm{~h}$ of strongest SLP deepening. Based on the values for cyclone intensification and WCB strength, three cyclone categories have been distinguished: explosively intensifying cyclones with a strong WCB $(\mathrm{C} 1)$, weak cyclones with a strong WCB (C2), and explosively intensifying cyclones with a weak WCB (C3). Their structure and evolution has been analyzed using composites. The questions posed in the introduction can be answered as follows:

1) The statistical analysis of the relationship between cyclone intensification and WCB strength yields a Spearman correlation coefficient of 0.68 . This implies that there is statistically a clear signal that stronger intensifying cyclones have stronger WCBs, which contribute to the diabatic production of cyclonic low-level PV. This result is in harmony with the results of many case studies (see introduction) and with the climatological analysis of Čampa and Wernli (2012) that low-level PV production due to latent heating in clouds is typically enhanced in explosive cyclones and contributes to the formation of the lower part of the cyclones' PV towers. An important new result of this study is that this low-level PV production occurs essentially in WCBs. However, the majority of the cyclones is associated with a weak deepening and few or no WCB trajectories, while the strongly deepening cyclones with an intense WCB occur less frequently.

2) Explosively intensifying cyclones with a strong WCB (C1) are typically characterized by intense PV production in the cyclone center related to a WCB of type W2, the interaction of the diabatically produced low-level vortex with a cyclonically breaking upper-level wave 
and a surface warm anomaly, and the formation of an upright PV tower toward the end of strongest intensification. The diabatically generated PV anomaly within the ascending WCB significantly enhances the low-level circulation and thereby contributes to the explosive intensification.

3)(i) Cyclones with a similar WCB strength as in $\mathrm{C} 1$ but a weak deepening rate $(\mathrm{C} 2)$ are divided into two subcategories:

C2a: DRW-like cyclones associated with strong low-level PV production by WCBs in the cyclone center in a baroclinic region, but a weak upperlevel forcing for ascent, which prevents the formation of an intense cyclone. The existence of WCB airstreams in DRWs despite the absence of significant upper-level forcing is particularly interesting, as it implies that in these cases the strong ascent must be almost entirely driven by the slantwise circulation over the baroclinic region induced by the low-level vortex.

C2b: Cyclones with substantial PV production along the pronounced cold front far away from the cyclone center in WCBs of type W1. This results in a weaker low-level PV anomaly in the cyclone center in comparison to $\mathrm{C} 1$, and in addition, the cyclones are associated with a weaker upper-level forcing for ascent. For these cyclones the diabatic $\mathrm{PV}$ production in the $\mathrm{WCB}$ and the dry dynamical ingredients are not in phase, which inhibits rapid intensification. Further investigations are needed to better understand this behavior, which however occurs much less frequently than the synergetic phasing of the anomalies (500 cyclones in category $\mathrm{C} 1$ vs only 72 in category $\mathrm{C} 2 \mathrm{~b}$ ).

3)(ii) The category of explosively intensifying cyclones with a weak WCB (C3) is inhomogeneous and can approximately be classified as follows: (i) particularly strong upper-level forcing for ascent (e.g., at the left jet exit); (ii) important role of WCB-related PV production, although the WCB is associated with few trajectories; (iii) important role of diabatic $\mathrm{PV}$ production not related to WCBs; and (iv) merging of cyclones leading to a rapid SLP decrease. Often, the cyclones also reveal a combination of these characteristics.

The findings for the different categories are fairly robust to the measure used to quantify cyclone intensification, as shown in the supplemental material. In addition, very similar results are obtained when using as a measure of WCB strength the number of WCB trajectories normalized by the size of the cyclones (not shown). Two aspects of the previously summarized key findings deserve a brief further discussion: (i) the relative importance of W1 and W2 WCBs for cyclone intensification and (ii) the link to moist baroclinic instability studies.

In many explosively intensifying cyclones (category C1) there is a remarkable concentration of the WCBrelated PV production in the cyclone center. This shows that these cyclones are predominantly associated with a WCB of type W2, which ascends close to the cyclone center above the bent-back front (e.g., Browning and Roberts 1994; Wernli 1997). The results of this study imply that the ascent in the cyclone center, which leads to the type $\mathrm{W} 2 \mathrm{WCB}$, is strongly determined by the QG upper-level forcing for vertical motion (Fig. 8b). The WCB associated with the weakly intensifying C2b cyclones, on the other hand, fits well with the description of type W1, particularly the part of the WCB ascending far away from the cyclone center. This demonstrates that WCBs of type W1 and W2 are dynamically distinct flows that have strongly differing effects on cyclone intensification. W2 WCBs significantly enhance cyclone intensification through intense low-level PV production close to the cyclone center, in contrast to W1 WCBs, where the low-level PV production occurs too far away from the cyclone center. The position of the WCB ascent relative to the cyclone center, and the processes determining this position, therefore play a crucial role for the evolution of the cyclone.

Establishing a link between our results and idealized baroclinic instability studies (e.g., De Vries et al. 2010; Cohen and Boos 2016) is not straightforward mainly because we focus on the period of maximum intensification when finite-amplitude anomalies interact nonlinearly. For $\mathrm{C} 1$ cyclones, the strongest growth during the $24 \mathrm{~h}$ of maximum deepening occurs for the low-level PV anomaly (Figs. 7 and S1). The upper-level PV anomaly also shows considerable intensification (Fig. 7) while the surface potential temperature anomaly intensifies much less (Fig. S2). This indicates that for $\mathrm{C} 1$ cyclones the favorable interaction between upper-level (dry) PV and low-level (diabatically generated) PV is essential, which was referred to as a "tropopause intrusion" by Cohen and Boos (2016) and as "type-C baroclinic growth" by De Vries et al. (2010). The latter terminology would be consistent with Plant et al. (2003) and Ahmadi-Givi et al. (2004), who also emphasized the interaction of prominent upper- and low-level PV anomalies for type $\mathrm{C}$ cyclones while surface thermal anomalies remain weak. For $\mathrm{C} 2 \mathrm{a}$ cyclones, the most important anomalies are clearly those of low-level PV and surface potential temperature, which we consider as typical for diabatic Rossby waves (e.g., Boettcher and Wernli 2011). This however differs from the diabatic 
Rossby wave definition in the more idealized studies cited above. For $\mathrm{C} 2 \mathrm{~b}$ and $\mathrm{C} 3$, a one-to-one attribution with any of the idealized categories is even more difficult.

Finally, it is noted as a caveat that this study is based on relatively coarse-resolution reanalysis data, and that with the compositing technique, we focused on robust PV structures on the subsynoptic scale $(\sim 500 \mathrm{~km})$. It is however known that cyclones also reveal important mesoscale PV structures (e.g., Thorpe and Clough 1991; Neiman et al. 1993). Investigation of the formation of these PV anomalies and their relationship to the WCB and its associated microphysical processes requires the use of a high-resolution mesoscale model. This route of research has so far only been applied for selected case studies (e.g., Joos and Wernli 2012). In addition, the approach used in this climatological study is potentially useful for quantitatively assessing cyclone dynamics in climate models. Catto et al. (2010) analyzed whether climate models can capture the overall structure of extratropical cyclones; the framework developed here could serve to analyze the interaction of latent heating and cyclone dynamics in these models in greater detail.

Acknowledgments. H. Binder and M. Boettcher acknowledge funding by the Swiss National Science Foundation (Project 200020_146834). We thank Michael Sprenger (ETH Zürich) for his continuous technical support and Bojan Škerlak (formerly at ETH Zürich) for providing the gridding tool. We are grateful to Sue Gray (University of Reading) for providing the QG vertical motion diagnostic from the NDDIAG routines and to Julian Quinting (formerly at ETH Zürich) and three anonymous reviewers for valuable comments and suggestions. ECMWF and MeteoSwiss are acknowledged for granting access to the ERA-Interim dataset.

\section{REFERENCES}

Ahmadi-Givi, F., G. C. Craig, and R. S. Plant, 2004: The dynamics of a midlatitude cyclone with very strong latent-heat release. Quart. J. Roy. Meteor. Soc., 130, 295-324, doi:10.1256/ qj.02.226.

Anthes, R. A., Y.-H. Kuo, and J. R. Gyakum, 1983: Numerical simulations of a case of explosive marine cyclogenesis. Mon. Wea. Rev., 111, 1174-1188, doi:10.1175/1520-0493(1983)111<1174: $\mathrm{NSOACO}>2.0 . \mathrm{CO} ; 2$.

Atlas, R., 1987: The role of oceanic fluxes and initial data in the numerical prediction of an intense coastal storm. Dyn. Atmos. Oceans, 10, 359-388, doi:10.1016/0377-0265(87)90025-X.

Badger, J., and B. Hoskins, 2001: Simple initial value problems and mechanisms for baroclinic growth. J. Atmos. Sci., 58, 38-49, doi:10.1175/1520-0469(2001)058<0038:SIVPAM >2.0.CO;2.

Bengtsson, L., K. I. Hodges, and N. Keenlyside, 2009: Will extratropical storms intensify in a warmer climate? J. Climate, 22, 2276-2301, doi:10.1175/2008JCLI2678.1.
Boettcher, M., and H. Wernli, 2011: Life cycle study of a diabatic Rossby wave as a precursor to rapid cyclogenesis in the North Atlantic-Dynamics and forecast performance. Mon. Wea. Rev., 139, 1861-1878, doi:10.1175/2011MWR3504.1.

— and - 2013: A 10-yr climatology of diabatic Rossby waves in the Northern Hemisphere. Mon. Wea. Rev., 141, 1139-1154, doi:10.1175/MWR-D-12-00012.1.

Booth, J. F., S. Wang, and L. Polvani, 2013: Midlatitude storms in a moister world: Lessons from idealized baroclinic life cycle experiments. Climate Dyn., 41, 787-802, doi:10.1007/ s00382-012-1472-3.

Bosart, L. F., 1981: The Presidents' Day snowstorm of 18-19 February 1979: A subsynoptic-scale event. Mon. Wea. Rev., 109, 1542-1566, doi:10.1175/1520-0493(1981)109<1542:TPDSOF>2.0.CO;2.

Browning, K. A., 1990: Organization of clouds and precipitation in extratropical cyclones. Extratropical Cyclones: The Erik Palmén Memorial Volume, C. W. Newton and E. O. Holopainen, Eds. Amer. Meteor. Soc., 129-153.

_ 1999: Mesoscale aspects of extratropical cyclones: An observational perspective. The Life Cycles of Extratropical Cyclones, M. A. Shapiro and S. Grønås, Eds., Springer, 265-283, doi:10.1007/ 978-1-935704-09-6_18.

—_, and N. M. Roberts, 1994: Structure of a frontal cyclone. Quart. J. Roy. Meteor. Soc., 120, 1535-1557, doi:10.1002/ qj.49712052006.

—, M. E. Hardman, T. W. Harrold, and C. W. Pardoe, 1973: The structure of rainbands within a mid-latitude depression. Quart. J. Roy. Meteor. Soc., 99, 215-231, doi:10.1002/qj.49709942002.

Campa, J., and H. Wernli, 2012: A PV perspective on the vertical structure of mature midlatitude cyclones in the Northern Hemisphere. J. Atmos. Sci., 69, 725-740, doi:10.1175/JAS-D-11-050.1.

Carlson, T. N., 1980: Airflow through midlatitude cyclones and the comma cloud pattern. Mon. Wea. Rev., 108, 1498-1509, doi:10.1175/1520-0493(1980)108<1498:ATMCAT>2.0.CO;2.

Catto, J. L., L. C. Shaffrey, and K. I. Hodges, 2010: Can climate models capture the structure of extratropical cyclones? J. Climate, $\mathbf{2 3}$, 1621-1635, doi:10.1175/2009JCLI3318.1.

Clough, S. A., C. S. A. Davitt, and A. J. Thorpe, 1996: Attribution concepts applied to the omega equation. Quart. J. Roy. Meteor. Soc., 122, 1943-1962, doi:10.1002/qj.49712253610.

Cohen, N. Y., and W. R. Boos, 2016: Perspectives on moist baroclinic instability: Implications for the growth of monsoon depressions. J. Atmos. Sci., 73, 1767-1788, doi:10.1175/ JAS-D-15-0254.1.

Coronel, B., D. Ricard, G. Rivière, and P. Arbogast, 2015: Role of moist processes in the tracks of idealized midlatitude surface cyclones. J. Atmos. Sci., 72, 2979-2996, doi:10.1175/ JAS-D-14-0337.1.

Dacre, H. F., and S. L. Gray, 2013: Quantifying the climatological relationship between extratropical cyclone intensity and atmospheric precursors. Geophys. Res. Lett., 40, 2322-2327, doi:10.1002/grl.50105.

— M. K. Hawcroft, M. A. Stringer, and K. I. Hodges, 2012: An extratropical cyclone atlas: A tool for illustrating cyclone structure and evolution characteristics. Bull. Amer. Meteor. Soc., 93, 1497-1502, doi:10.1175/BAMS-D-11-00164.1.

Davis, C. A., and K. A. Emanuel, 1991: Potential vorticity diagnostics of cyclogenesis. Mon. Wea. Rev., 119, 1929-1953, doi:10.1175/1520-0493(1991)119<1929:PVDOC>2.0.CO;2.

_, M. T. Stoelinga, and Y.-H. Kuo, 1993: The integrated effect of condensation in numerical simulations of extratropical cyclogenesis. Mon. Wea. Rev., 121, 2309-2330, doi:10.1175/ 1520-0493(1993)121<2309:TIEOCI >2.0.CO;2. 
Dee, D. P., and Coauthors, 2011: The ERA-Interim reanalysis: Configuration and performance of the data assimilation system. Quart. J. Roy. Meteor. Soc., 137, 553-597, doi:10.1002/ qj.828.

Deveson, A. C. L., K. A. Browning, and T. D. Hewson, 2002: A classification of FASTEX cyclones using a height-attributable quasi-geostrophic vertical-motion diagnostic. Quart. J. Roy. Meteor. Soc., 128, 93-117, doi:10.1256/00359000260498806.

De Vries, H., J. Methven, T. H. A. Frame, and B. J. Hoskins, 2010: Baroclinic waves with parameterized effects of moisture interpreted using Rossby wave components. J. Atmos. Sci., 67, 2766-2784, doi:10.1175/2010JAS3410.1.

Eady, E. T., 1949: Long waves and cyclone waves. Tellus, 1, 33-52, doi:10.1111/j.2153-3490.1949.tb01265.x.

Eckhardt, S., A. Stohl, H. Wernli, P. James, C. Forster, and N. Spichtinger, 2004: A 15-year climatology of warm conveyor belts. J. Climate, 17, 218-237, doi:10.1175/ 1520-0442(2004)017<0218:AYCOWC>2.0.CO;2.

Emanuel, K. A., M. Fantini, and A. J. Thorpe, 1987: Baroclinic instability in an environment of small stability to slantwise moist convection. Part I: Two-dimensional models. J. Atmos. Sci., 44, 1559-1573, doi:10.1175/1520-0469(1987)044<1559: BIIAEO $>2.0 . \mathrm{CO} ; 2$.

Field, P. R., and R. Wood, 2007: Precipitation and cloud structure in midlatitude cyclones. J. Climate, 20, 233-254, doi:10.1175/ JCLI3998.1.

Fink, A. H., S. Pohle, J. G. Pinto, and P. Knippertz, 2012: Diagnosing the influence of diabatic processes on the explosive deepening of extratropical cyclones. Geophys. Res. Lett., 39, L07803, doi:10.1029/2012GL051025.

Grams, C. M., and Coauthors, 2011: The key role of diabatic processes in modifying the upper-tropospheric wave guide: A North Atlantic case-study. Quart. J. Roy. Meteor. Soc., 137, 2174-2193, doi:10.1002/qj.891.

Gyakum, J. R., 1983a: On the evolution of the $Q E$ II storm. I: Synoptic aspects. Mon. Wea. Rev., 111, 1137-1155, doi:10.1175/ 1520-0493(1983)111<1137:OTEOTI > 2.0.CO;2.

, 1983b: On the evolution of the $Q E I I$ storm. II: Dynamic and thermodynamic structure. Mon. Wea. Rev., 111, 1156-1173, doi:10.1175/1520-0493(1983)111<1156:OTEOTI > 2.0.CO;2.

_ J. R. Anderson, R. H. Grumm, and E. L. Gruner, 1989: North Pacific cold-season surface cyclone activity: 1975-1983. Mon Wea. Rev., 117, 1141-1155, doi:10.1175/1520-0493(1989)117<1141: NPCSSC $>2.0 . C O ; 2$.

Harrold, T. W., 1973: Mechanisms influencing the distribution of precipitation within baroclinic disturbances. Quart. J. Roy. Meteor. Soc., 99, 232-251, doi:10.1002/qj.49709942003.

Hoskins, B. J., 1990: Theory of extratropical cyclones. Extratropical Cyclones: The Erik Palmén Memorial Volume, C. W. Newton and E. O. Holopainen, Eds., Amer. Meteor. Soc., 63-80.

-, M. E. McIntyre, and A. W. Robertson, 1985: On the use and significance of isentropic potential vorticity maps. Quart. J. Roy. Meteor. Soc., 111, 877-946, doi:10.1002/qj.49711147002.

Joos, H., and H. Wernli, 2012: Influence of microphysical processes on the potential vorticity development in a warm conveyor belt: A case-study with the limited-area model COSMO. Quart. J. Roy. Meteor. Soc., 138, 407-418, doi:10.1002/qi.934.

Knapp, K. R., and Coauthors, 2011: Globally gridded satellite observations for climate studies. Bull. Amer. Meteor. Soc., 92 , 893-907, doi:10.1175/2011BAMS3039.1.

Liberato, M. L. R., J. G. Pinto, R. M. Trigo, P. Ludwig, P. Ordóñez, D. Yuen, and I. F. Trigo, 2013: Explosive development of winter storm Xynthia over the subtropical North Atlantic
Ocean. Nat. Hazards Earth Syst. Sci., 13, 2239-2251, doi:10.5194/ nhess-13-2239-2013.

Ludwig, P., J. G. Pinto, M. Reyers, and S. L. Gray, 2014: The role of anomalous SST and surface fluxes over the southeastern North Atlantic in the explosive development of windstorm Xynthia. Quart. J. Roy. Meteor. Soc., 140, 1729-1741, doi:10.1002/qj.2253.

Madonna, E., H. Wernli, H. Joos, and O. Martius, 2014: Warm conveyor belts in the ERA-Interim dataset (1979-2010). Part I: Climatology and potential vorticity evolution. J. Climate, 27, 3-26, doi:10.1175/JCLI-D-12-00720.1.

Mak, M., 1982: On moist quasi-geostrophic baroclinic instability. $J$. Atmos. Sci., 39, 2028-2037, doi:10.1175/1520-0469(1982)039<2028: OMQGBI $>2.0 . \mathrm{CO} ; 2$

Martínez-Alvarado, O., H. Joos, J. Chagnon, M. Boettcher, S. L. Gray, R. S. Plant, J. Methven, and H. Wernli, 2014: The dichotomous structure of the warm conveyor belt. Quart. J. Roy. Meteor. Soc., 140, 1809-1824, doi:10.1002/qj.2276.

Massacand, A. C., H. Wernli, and H. C. Davies, 2001: Influence of upstream diabatic heating upon an Alpine event of heavy precipitation. Mon. Wea. Rev., 129, 2822-2828, doi:10.1175/ 1520-0493(2001)129<2822:IOUDHU>2.0.CO;2.

Methven, J., 2015: Potential vorticity in warm conveyor belt outflow. Quart. J. Roy. Meteor. Soc., 141, 1065-1071, doi:10.1002/qj.2393.

Neiman, P. J., M. A. Shapiro, and L. S. Fedor, 1993: The life cycle of an extratropical marine cyclone. Part II: Mesoscale structure and diagnostics. Mon. Wea. Rev., 121, 2177-2199, doi:10.1175/ 1520-0493(1993)121<2177:TLCOAE > 2.0.CO;2.

Nicosia, D. J., and R. H. Grumm, 1999: Mesoscale band formation in three major northeastern United States snowstorms. Wea. Forecasting, 14, 346-368, doi:10.1175/1520-0434(1999)014<0346: MBFITM $>2.0 . \mathrm{CO} ; 2$.

Parker, D. J., and A. J. Thorpe, 1995: Conditional convective heating in a baroclinic atmosphere: A model of convective frontogenesis. J. Atmos. Sci., 52, 1699-1711, doi:10.1175/ 1520-0469(1995)052<1699:CCHIAB > 2.0.CO;2.

Pfahl, S., E. Madonna, M. Boettcher, H. Joos, and H. Wernli, 2014: Warm conveyor belts in the ERA-Interim dataset (19792010). Part II: Moisture origin and relevance for precipitation. J. Climate, 27, 27-40, doi:10.1175/JCLI-D-13-00223.1.

Plant, R. S., G. C. Craig, and S. L. Gray, 2003: On a threefold classification of extratropical cyclogenesis. Quart. J. Roy. Meteor. Soc., 129, 2989-3012, doi:10.1256/qj.02.174.

Pomroy, H. R., and A. J. Thorpe, 2000: The evolution and dynamical role of reduced upper-tropospheric potential vorticity in intensive observing period one of FASTEX. Mon. Wea. Rev., 128, 1817-1834, doi:10.1175/1520-0493(2000)128<1817: TEADRO $>2.0 . \mathrm{CO} ; 2$.

Reed, R. J., M. T. Stoelinga, and Y.-H. Kuo, 1992: A model-aided study of the origin and evolution of the anomalously high potential vorticity in the inner region of a rapidly deepening marine cyclone. Mon. Wea. Rev., 120, 893-913, doi:10.1175/ 1520-0493(1992)120<0893:AMASOT>2.0.CO;2.

Rivière, G., P. Arbogast, K. Maynard, and A. Joly, 2010: The essential ingredients leading to the explosive growth stage of the European wind storm Lothar of Christmas 1999. Quart. J. Roy. Meteor. Soc., 136, 638-652, doi:10.1002/qj.585.

Roebber, P. J., 1984: Statistical analysis and updated climatology of explosive cyclones. Mon. Wea. Rev., 112, 1577-1589, doi:10.1175/ 1520-0493(1984)112<1577:SAAUCO > 2.0.CO;2.

Rossa, A. M., H. Wernli, and H. C. Davies, 2000: Growth and decay of an extra-tropical cyclones PV-tower. Meteor. Atmos. Phys., 73, 139-156, doi:10.1007/s007030050070. 
Sanders, F., and J. R. Gyakum, 1980: Synoptic-dynamic climatology of the "bomb." Mon. Wea. Rev., 108, 1589-1606, doi:10.1175/ 1520-0493(1980)108<1589:SDCOT>2.0.CO;2.

Schemm, S., H. Wernli, and L. Papritz, 2013: Warm conveyor belts in idealized moist baroclinic wave simulations. J. Atmos. Sci., 70, 627-652, doi:10.1175/JAS-D-12-0147.1.

Shapiro, M. A., and D. A. Keyser, 1990: Fronts, jet streams, and the tropopause. Extratropical Cyclones: The Erik Palmén Memorial Volume, C. W. Newton and E. O. Holopainen, Eds., Amer. Meteor. Soc., 169-191.

Simmons, A., S. Uppala, D. Dee, and S. Kobayashi, 2007: ERAInterim: New ECMWF reanalysis products from 1989 onwards. ECMWF Newsletter, No. 110, ECMWF, Reading, United Kingdom, 25-35.

Spearman, C., 1904: The proof and measurement of association between two things. Amer. J. Psychol., 15, 72-101, doi:10.2307/ 1412159.

Sprenger, M., and H. Wernli, 2015: The LAGRANTO Lagrangian analysis tool-Version 2.0. Geosci. Model Dev., 8, 2569-2586, doi:10.5194/gmd-8-2569-2015.

Stoelinga, M. T., 1996: A potential vorticity-based study of the role of diabatic heating and friction in a numerically simulated baroclinic cyclone. Mon. Wea. Rev., 124, 849-874, doi:10.1175/ 1520-0493(1996)124<0849:APVBSO > 2.0.CO;2.

Tamarin, T., and Y. Kaspi, 2016: The poleward motion of extratropical cyclones from a potential vorticity tendency analysis. J. Atmos. Sci., 73, 1687-1707, doi:10.1175/JAS-D-15-0168.1.

Thorncroft, C. D., B. J. Hoskins, and M. E. McIntyre, 1993: Two paradigms of baroclinic-wave life-cycle behaviour. Quart. J. Roy. Meteor. Soc., 119, 17-55, doi:10.1002/qj.49711950903.

Thorpe, A. J., and S. A. Clough, 1991: Mesoscale dynamics of cold fronts: Structures described by dropsoundings in FRONTS 87. Quart. J. Roy. Meteor. Soc., 117, 903-941, doi:10.1002/ qj.49711750103.
Uccellini, L. W., 1990: Processes contributing to the rapid development of extratropical cyclones. Extratropical Cyclones: The Erik Palmén Memorial Volume, C. W. Newton and E. O. Holopainen, Eds., Amer. Meteor. Soc., 81-105.

Ulbrich, U., A. H. Fink, M. Klawa, and J. G. Pinto, 2001: Three extreme storms over Europe in December 1999. Weather, 56, 70-80, doi:10.1002/j.1477-8696.2001.tb06540.x.

Wernli, H., 1997: A Lagrangian-based analysis of extratropical cyclones. II: A detailed case-study. Quart. J. Roy. Meteor. Soc., 123, 1677-1706, doi:10.1002/qj.49712354211.

_ , and H. C. Davies, 1997: A Lagrangian-based analysis of extratropical cyclones. I: The method and some applications. Quart. J. Roy. Meteor. Soc., 123, 467-489, doi:10.1002/qj.49712353811.

, and C. Schwierz, 2006: Surface cyclones in the ERA-40 dataset (1958-2001). Part I: Novel identification method and global climatology. J. Atmos. Sci., 63, 2486-2507, doi:10.1175/ JAS3766.1.

_ , S. Dirren, M. A. Liniger, and M. Zillig, 2002: Dynamical aspects of the life cycle of the winter storm 'Lothar' (24-26 December 1999). Quart. J. Roy. Meteor. Soc., 128, 405-429, doi:10.1256/003590002321042036.

Whitaker, J. S., and C. A. Davis, 1994: Cyclogenesis in a saturated environment. J. Atmos. Sci., 51, 889-908, doi:10.1175/ 1520-0469(1994)051<0889:CIASE>2.0.CO;2.

— L. W. Uccellini, and K. F. Brill, 1988: A model-based diagnostic study of the rapid development phase of the Presidents's Day cyclone. Mon. Wea. Rev., 116, 2337-2365, doi:10.1175/1520-0493(1988)116<2337:AMBDSO>2.0.CO;2.

Young, M., G. Monk, and K. Browning, 1987: Interpretation of satellite imagery of a rapidly deepening cyclone. Quart. J. Roy. Meteor. Soc., 113, 1089-1115, doi:10.1002/qj.49711347803.

Zhang, F., C. Snyder, and R. Rotunno, 2002: Mesoscale predictability of the surprise snowstorm of 24-25 January 2000. Mon. Wea. Rev., 130, 1617-1632, doi:10.1175/1520-0493(2002)130<1617: MPOTSS $>2.0 . \mathrm{CO} ; 2$. 